\title{
Primary prevention of depression: An umbrella review of controlled interventions
}

\author{
Gonzalo Salazar de Pablo ${ }^{\text {a,b,ag }}$, Marco Solmi ${ }^{\text {a, ae, af }}$, Julio Vaquerizo-Serrano ${ }^{\text {b,z,ag, }}$, \\ Joaquim Radua ${ }^{\text {a,c,d }}$, Anastassia Passina ${ }^{a}$, Pierluca Mosillo ${ }^{a}$, Christoph U Correll ${ }^{\text {e,f,g }}$, \\ Stefan Borgwardt ${ }^{\mathrm{h}, \mathrm{i}}$, Silvana Galderisi ${ }^{\mathrm{j}}$, Andreas Bechdolf $^{\mathrm{k}, 1, \mathrm{~m}, \mathrm{n}}$, Andrea Pfennig ${ }^{\mathrm{o}}$, \\ Michael Bauer ${ }^{\circ}$, Lars Vedel Kessing ${ }^{\mathrm{p}, \mathrm{q}}$, Therese van Amelsvoort ${ }^{\mathrm{r}}$, Dorien H. Nieman ${ }^{\mathrm{s}}$, \\ Katharina Domschke ${ }^{\mathrm{t}, \mathrm{u}}$, Marie-Odile Krebs ${ }^{\mathrm{v}, \mathrm{w}}$, Michael Sand ${ }^{\mathrm{x}}$, Eduard Vieta ${ }^{\mathrm{y}}$, \\ Philip McGuire ${ }^{\mathrm{z}, \mathrm{aa}, \mathrm{ab}}$, Celso Arango ${ }^{\mathrm{b}}$, Jae Il Shin ${ }^{\mathrm{ac}}$, Paolo Fusar-Poli ${ }^{\mathrm{a}, \mathrm{aa}, \mathrm{ab}, \mathrm{ad},{ }^{*}}$
}

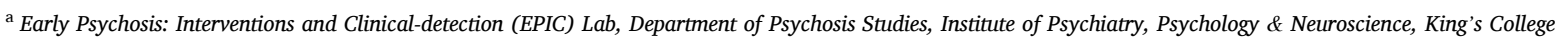
London, London, UK

${ }^{\mathrm{b}}$ Institute of Psychiatry and Mental Health. Department of Child and Adolescent Psychiatry, Hospital General Universitario Gregorio Marañón School of Medicine, Universidad Complutense, Instituto de Investigación Sanitaria Gregorio Marañón (IiSGM), CIBERSAM, Madrid, Spain

${ }^{\mathrm{c}}$ Imaging of Mood- and Anxiety-Related Disorders (IMARD) Group, Institut d'Investigacions Biomèdiques August Pi I Sunyer (IDIBAPS), CIBERSAM, Barcelona, Catalonia, Spain

d Department of Clinical Neuroscience, Centre for Psychiatric Research and Education, Karolinska Institutet, Stockholm, Sweden

e The Zucker Hillside Hospital, Department of Psychiatry, Northwell Health, Glen Oaks, NY, USA

${ }^{\mathrm{f}}$ The Feinstein Institute for Medical Research, Center for Psychiatric Neuroscience, Manhasset, NY, USA

${ }^{g}$ Charité Universitätsmedizin Berlin, Department of Child and Adolescent Psychiatry, Berlin, Germany

${ }^{\mathrm{h}}$ Department of Psychiatry, University of Basel, Switzerland

${ }^{i}$ Department of Psychiatry, Psychosomatics and Psychotherapy, University of Lübeck, Lübeck, Germany

${ }^{\mathrm{j}}$ Department of Psychiatry, University of Campania L. Vanvitelli, Naples, Italy

${ }^{\mathrm{k}}$ Department of Psychiatry, Psychotherapy and Psychosomatic Medicine with Early Intervention and Recognition Centre (FRITZ), Vivantes Klinikum Am Urban, ChariteUniversitätsmedizin, Berlin, Germany

${ }^{1}$ Vivantes Klinikum im Friedrichshain, Department of Psychiatry, Psychotherapy and Psychosomatic Medicine, Charité-Universitätsmedizin, Berlin, Germany

${ }^{\mathrm{m}}$ Department of Psychiatry and Psychotherapy, University of Cologne, Cologne, Germany

${ }^{\mathrm{n}}$ ORYGEN, The National Centre of Excellence in Youth Mental Health, Melbourne, Victoria, Australia

${ }^{\circ}$ Department of Psychiatry and Psychotherapy, Carl Gustav Carus University Hospital, Technische Universität Dresden, Dresden, Germany

${ }^{\mathrm{p}}$ Copenhagen Affective Disorder Research Center (CADIC), Psychiatric Center Copenhagen, Rigshospitalet, Copenhagen, Denmark

${ }^{\mathrm{q}}$ Department of Clinical Medicine, University of Copenhagen, Denmark

${ }^{\mathrm{r}}$ Maastricht University Medical Center, Department of Psychiatry and Neuropsychology, School for Mental Health and Neuroscience, Maastricht, The Netherlands

${ }^{s}$ Amsterdam University Medical Centers (location AMC), Department of Psychiatry, Amsterdam, Netherlands

${ }^{\mathrm{t}}$ Department of Psychiatry and Psychotherapy, Medical Center - University of Freiburg, Faculty of Medicine, University of Freiburg, Freiburg, Germany

"Center for Basics in NeuroModulation (NeuroModul), Medical Faculty, University of Freiburg, Germany

${ }^{v}$ INSERM, IPNP UMR S1266, Laboratoire de Physiopathologie des Maladies Psychiatriques, Universite de Paris, CNRS, GDR3557-Institut de Psychiatrie Paris, France

${ }^{\mathrm{w}}$ Faculté de Médecine Paris Descartes, GHU Paris - Sainte-Anne, Pole PEPIT Paris, France

${ }^{\mathrm{x}}$ Boehringer Ingelheim Pharmaceuticals, Ridgefield, Connecticut

${ }^{\mathrm{y}}$ Hospital Clinic, Institute of Neuroscience, University of Barcelona, IDIBAPS, CIBERSAM, Barcelona, Catalonia, Spain

${ }^{\mathrm{z}}$ Department of Psychosis Studies, Institute of Psychiatry, Psychology \& Neuroscience, King's College London, London, UK

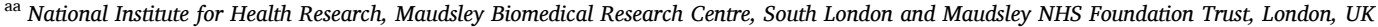

${ }^{\text {ab }}$ OASIS service, South London and Maudsley NHS Foundation Trust, London, UK

${ }^{\text {ac }}$ Department of Paediatrics, Yonsei University College of Medicine, Seoul, Republic of Korea

${ }^{\text {ad }}$ Department of Brain and Behavioral Sciences, University of Pavia, Pavia, Italy

ae Department of Psychiatry, University of Ottawa

af Department of Mental Health, The Ottawa Hospital

${ }^{\mathrm{ag}}$ Department of Child and Adolescent Psychiatry, Institute of Psychiatry, Psychology and Neuroscience, King's College London, London, UK

\footnotetext{
* Corresponding author: Dr. Paolo Fusar-Poli MD PhD, Department of Psychosis Studies, 5th Floor, Institute of Psychiatry, Psychology \& Neuroscience, PO63, 16 De Crespigny Park, SE5 8AF London, UK

E-mail address: paolo.fusar-poli@kcl.ac.uk (P. Fusar-Poli).
} 
A R T I C L E I N F O

\section{Keywords:}

Depression

Prevention, Evidence, Prediction, Metaanalysis

\section{A B S T R A C T}

Background: Primary prevention has the potential to modify the course of depression, but the consistency and magnitude of this effect are currently undetermined.

Methods: PRISMA and RIGHT compliant (PROSPERO:CRD42020179659) systematic meta-review, PubMed/ Web of Science, up to June 2020. Meta-analyses of controlled interventions for the primary prevention of depressive symptoms [effect measures: standardized mean difference (SMD)] or depressive disorders [effect measure: relative risk (RR)] were carried out. Results were stratified by: (i) age range; (ii) target population (general and/or at-risk); (iii) intervention type. Quality (assessed with AMSTAR/AMSTAR-PLUS content) and credibility (graded as high/moderate/low) were assessed. USPSTF grading system was used for recommendations.

Results: Forty-six meta-analyses ( $\mathrm{k}=928$ individual studies, $\mathrm{n}=286,429$ individuals, mean age $=22.4$ years, $81.1 \%$ female) were included. Effect sizes were: $\mathrm{SMD}=0.08-0.53$; for depressive symptoms; $\mathrm{RR}=0.90-0.28$ for depressive disorders. Sensitivity analyses including only RCTs did not impact the findings. AMSTAR median $=9$ (IQR=8-9); AMSTAR-PLUS content median=4.25 (IQR=4-5). Credibility of the evidence was insufficient/low in $43(93.5 \%)$ meta-analyses, moderate in two (4.3\%), and high in one (2.2\%): reduction of depressive symptoms using psychosocial interventions for young adults only, and a combination of psychological and educational interventions in primary care had moderate credibility; preventive administration of selective serotonin reuptake inhibitors (SSRIs) for depressive disorders in individuals with a stroke had high credibility.

Limitations: Intervention heterogeneity and lack of long-term efficacy evaluation.

Conclusions: Primary preventive interventions for depression might be effective. Among them, clinicians may offer SSRIs post-stroke to prevent depressive disorders, and psychosocial interventions for children/adolescents/ young adults with risk factors or during the prenatal/perinatal period.
Depression is a common mental disorder, associated with increased morbidity and mortality (American Psychiatric Association, 2013). Depressive symptoms, core features of depressive disorders, may appear full-blown (American Psychiatric Association, 2013) or in a subclinical/attenuated fashion (Salazar de Pablo et al., 2020a). The median age of the onset of depressive disorders typically lies in the early to mid-20s (Fusar-Poli, 2019), although symptoms may appear earlier, during childhood or adolescence. Depressive episodes often recur or become chronic, and this has detrimental consequences over the entire life span regarding both psychical and mental health (Solmi et al., 2020b). Depressive disorders are expected to be the largest cause of disease burden worldwide by 2030 (Lépine and Briley, 2011).

Prevention of mental disorders and poor mental health outcomes is an emerging approach in modern psychiatry (Arango et al., 2018; Fusar-Poli et al., 2019a). In particular, primary prevention of unipolar depressive disorders, encompassing indicated, selective or universal approaches (eTable 1), is a potential strategy to stop or at least decrease the severity or delay the onset of a disorder (Fusar-Poli et al., 2019a; Fusar-Poli et al., 2017). For primary prevention of depression to be implemented in clinical practice, the magnitude and consistency of the efficacy, the credibility of the evidence, the target population and the content of the intervention are core factors that need to be systematically appraised.

While several meta-analyses have attempted to partially answer some of these questions, their findings are often conflicting and inconclusive (Deady et al., 2017; Sander et al., 2016). No umbrella review (a review of meta-analyses (Fusar-Poli and Radua, 2018)) has systematically appraised the consistency and magnitude of primary prevention for depression. The objective of this study, produced by the European College of Neuropsychopharmacology Network on the Prevention of Mental Disorders and Mental Health Promotion (ECNP TWG PMD-MHP) (ECNP, 2019), was to summarize the evidence for the primary prevention of depression and provide evidence-based recommendations.

\section{Methods}

The protocol for this study was registered on PROSPERO (CRD42020179659). This study was conducted in accordance with the PRISMA 2020 item checklist (Page et al., 2021) (eTable 2) and RIGHT (Chen et al., 2017) statements.

\section{Search strategy}

A multi-step literature search was performed by two researchers (GSP, PM) in PubMed and Web of Science database (Clarivate Analytics), incorporating the Web of Science Core Collection, BIOSIS Citation Index, KCI-Korean Journal Database, MEDLINE, Russian Science Citation Index, and SciELO Citation Index as well as Cochrane Central Register of Reviews, and Ovid/PsycINFO databases from inception until 1st June 2020, in English. We used the following keywords: ("treatment" OR "intervention" OR "risk" OR "prodrom*" OR "prevention" OR "promotion" OR "early intervention" OR "clinical high risk" OR "attenuat”" OR "subclinical" OR "high risk" OR "risk of progression") AND ("depress" OR "mood" OR "MDD" OR "major depres*" OR "affective") AND "metaanalysis". We manually reviewed the references of previously published articles using MEDLINE and extracted additional relevant titles. Articles identified were screened as abstracts, and after the exclusion of those which did not meet our inclusion criteria, the full texts of the remaining articles were assessed for eligibility, and decisions were made regarding their inclusion in the review.

\section{Inclusion and exclusion criteria}

Studies included were a) meta-analyses (pairwise or network, aggregate or individual participant data), b) evaluating any primary preventive intervention for depressive symptoms and/or depressive disorders (universal, selective or indicated (Fusar-Poli et al., 2019a)), c) with a comparison condition, d) in a population without reported ICD/DSM diagnoses of depressive disorders, e) written in English. Studies excluded were a) individual studies, study protocols, conference proceedings, systematic reviews without quantitative analyses, grey literature or unpublished data and any other non-meta-analytical study, b) carried out in individuals already affected by an established ICD/DSM depressive disorder, c) aiming to prevent symptoms other than depressive symptoms or depressive disorders, d) focusing on the prevention of bipolar depression, e) not in English, f) with $<6 / 11$ total score in the "Assessing the Methodological Quality of Systematic Reviews" (AMSTAR) (Faggion, 2015).

To respect the hierarchy of the evidence (see eMethods 1 for rationale), if $\geq 2$ meta-analyses addressing the same intervention and targeting the same individuals were found, individual participant data meta-analyses were preferred over aggregate network meta-analyses, 
Table 1

Main characteristics of the included meta-analyses by age range and target population

\begin{tabular}{|c|c|c|c|c|c|c|}
\hline Study & Particular population & $\begin{array}{l}\text { Gordon's } \\
\text { classification }\end{array}$ & Setting & $\begin{array}{l}\text { Intervention } \\
\text { type }\end{array}$ & Comparison & Outcome \\
\hline \multicolumn{7}{|c|}{ Prenatal/perinatal period } \\
\hline \multicolumn{7}{|c|}{ General population + at-risk individuals } \\
\hline (O'Connor et al., 2019) & $\begin{array}{l}\text { Pregnant women or young } \\
\text { mothers }\end{array}$ & $\mathrm{U}, \mathrm{S}, \mathrm{I}$ & Any & Any & AC, NI, Placebo & Disorders \\
\hline (Dennis and Dowswell, 2013) & $\begin{array}{l}\text { Pregnant women or young } \\
\text { mothers }\end{array}$ & $\mathrm{U}, \mathrm{S}, \mathrm{I}$ & Any & PS & TAU & $\begin{array}{l}\text { Symptoms, } \\
\text { disorders }\end{array}$ \\
\hline $\begin{array}{l}\text { (Cluxton-Keller and Bruce, } \\
\text { 2018) }\end{array}$ & $\begin{array}{l}\text { Pregnant women or young } \\
\text { mothers }\end{array}$ & $\mathrm{U}, \mathrm{I}$ & Any & PS & NI, TAU, WL & Symptoms \\
\hline (Goodman et al., 2018) & $\begin{array}{l}\text { Pregnant women or young } \\
\text { mothers }\end{array}$ & $\mathrm{U}, \mathrm{S}, \mathrm{I}$ & Any & PS & N.a & $\begin{array}{l}\text { Symptoms, } \\
\text { disorders }\end{array}$ \\
\hline \multicolumn{7}{|l|}{ General population } \\
\hline $\begin{array}{l}\text { (Carter et al., 2019) } \\
\text { At-risk individuals }\end{array}$ & Postnatal women & $\mathrm{U}$ & Any & Exercise & AC, NI, Placebo & Symptoms \\
\hline (Benzies et al., 2013) & Postnatal women & $\mathrm{S}$ & Any & PS & AC, TAU & Symptoms \\
\hline \multicolumn{7}{|l|}{$\begin{array}{l}\text { General population }+ \text { at-risk } \\
\text { individuals }\end{array}$} \\
\hline (Hetrick et al., 2015) & Any & U, S I & Any & PS & AC, NI & $\begin{array}{l}\text { Symptoms, } \\
\text { disorders }\end{array}$ \\
\hline (Werner-Seidler et al., 2017) & Any & $\mathrm{U}, \mathrm{S}, \mathrm{I}$ & School & PS & AC, NI, WL & Symptoms \\
\hline (Hetrick et al., 2016) & Any & $\mathrm{U}, \mathrm{S}, \mathrm{I}$ & Any & CBT, IPT & AP, NI, TAU, WL & $\begin{array}{l}\text { Symptoms, } \\
\text { disorders }\end{array}$ \\
\hline (Brunwasser et al., 2009) & Any & $\mathrm{U}, \mathrm{S}, \mathrm{I}$ & Any & PRP & AC, NI, WL & $\begin{array}{l}\text { Symptoms, } \\
\text { disorders }\end{array}$ \\
\hline (Yap et al., 2016) & Any & $\mathrm{U}, \mathrm{S}, \mathrm{I}$ & Any & PARENT & AC, NI, TAU, WL & $\begin{array}{l}\text { Symptoms, } \\
\text { disorders }\end{array}$ \\
\hline (Stockings et al., 2016) & Any & $\mathrm{U}, \mathrm{S}, \mathrm{I}$ & Any & PHY & NI, Placebo, TAU & Disorders \\
\hline \multicolumn{7}{|l|}{ General population } \\
\hline (Ahlen et al., 2015) & Any & $\mathrm{U}$ & Any & PS & NI & Symptoms \\
\hline (Dray et al., 2017) & Any & $\mathrm{U}$ & Any & RFI & $\mathrm{AC}, \mathrm{NI}$ & Symptoms \\
\hline (Bastounis et al., 2016) & Any & $\mathrm{U}$ & Any & PRP & AC, NI, WL & $\begin{array}{l}\text { Symptoms, } \\
\text { disorders }\end{array}$ \\
\hline \multicolumn{7}{|l|}{ At-risk individuals } \\
\hline (Loechner et al., 2018) & Family history of depression & $\mathrm{S}$ & Any & PS & AC, TAU, WL & $\begin{array}{l}\text { Symptoms, } \\
\text { disorders }\end{array}$ \\
\hline (Rasing et al., 2017) & Any & $\mathrm{S}, \mathrm{I}$ & School and community & СBT & AC, NI, TAU & Symptoms \\
\hline (Ssegonja et al., 2019) & Subthreshold symptoms & I & Any & Group CBT & AC, TAU, WL & $\begin{array}{l}\text { Symptom, } \\
\text { disorders }\end{array}$ \\
\hline \multicolumn{7}{|l|}{ Adults } \\
\hline \multicolumn{7}{|l|}{$\begin{array}{l}\text { General population }+ \text { at-risk } \\
\text { individuals }\end{array}$} \\
\hline (Ma et al., 2019) & University students & $\mathrm{U}, \mathrm{I}$ & Any & MBI & NL, TAU, WL & Symptoms \\
\hline (Harrer et al., 2018) & University students & $\mathrm{U}, \mathrm{I}$ & Internet-based & ICT & AC, NI, Placebo, WL & Symptoms \\
\hline (Davies et al., 2014) & University students & $\mathrm{U}, \mathrm{I}$ & $\begin{array}{l}\text { Computer-delivered and } \\
\text { web-based }\end{array}$ & ICT & NI, WL & Symptoms \\
\hline (Breedvelt et al., 2018) & Young adults & $\mathrm{U}, \mathrm{S}, \mathrm{I}$ & Any & PS & $\begin{array}{l}\text { AC, Placebo, TAU, } \\
\text { WL }\end{array}$ & Symptoms \\
\hline (Sander et al., 2016) & Any & $\mathrm{U}, \mathrm{S}, \mathrm{I}$ & Any & ICT & $\begin{array}{l}\text { AC, NI, Placebo, } \\
\text { TAU, WL }\end{array}$ & Symptoms \\
\hline (Deady et al., 2017) & Any & $\mathrm{U}, \mathrm{S}, \mathrm{I}$ & Any & ICT, CBT & AC, TAU, WL & Symptoms \\
\hline (Deane et al., 2019) & Any & $\mathrm{U}, \mathrm{S}, \mathrm{I}$ & Any & Fatty acids & $\mathrm{AC}$ & Symptoms \\
\hline (Young et al., 2019) & Any & $\mathrm{U}, \mathrm{S}, \mathrm{I}$ & Any & B vitamins & Placebo & Symptoms \\
\hline \multicolumn{7}{|l|}{ General population } \\
\hline (Bellón et al., 2019) & Any & $\mathrm{U}$ & Workplace & PS & AC, placebo & Disorders \\
\hline (Tan et al., 2014) & Any & $\mathrm{U}$ & Workplace & PS & AC, NI, WL & Symptoms \\
\hline (Petrie et al., 2019) & Physicians & $\mathrm{U}$ & Any & PS & AC, NI, WL & Symptoms \\
\hline \multicolumn{7}{|l|}{ At-risk individuals } \\
\hline (Ehret and Sobieraj, 2014) & $\begin{array}{l}\text { Individuals with Hepatitis C } \\
\text { treated by IFN-a }\end{array}$ & s & Any & SSRIs & Placebo & $\begin{array}{l}\text { Symptoms, } \\
\text { disorders }\end{array}$ \\
\hline (Jiang et al., 2014) & $\begin{array}{l}\text { Individuals with Hepatitis C } \\
\text { treated by IFN-a }\end{array}$ & $\mathrm{s}$ & Any & SSRIs & Placebo & $\begin{array}{l}\text { Symptoms, } \\
\text { disorders }\end{array}$ \\
\hline (Gu et al., 2020) & Individuals with a stroke & $\mathrm{S}$ & Any & Antidepressants & Placebo & $\begin{array}{l}\text { Symptoms, } \\
\text { disorders }\end{array}$ \\
\hline (Zhou et al., 2020) & Individuals with a stroke & $\mathrm{S}$ & Any & SSRIs & Placebo & Disorders \\
\hline (Yi et al., 2010) & Individuals with a stroke & $\mathrm{S}$ & Any & Fluoxetine & Placebo & $\begin{array}{l}\text { Symptoms, } \\
\text { disorders }\end{array}$ \\
\hline (Feng et al., 2018) & Individuals with a stroke & s & Any & Sertraline & Placebo & $\begin{array}{l}\text { Symptoms, } \\
\text { disorders }\end{array}$ \\
\hline (Salter et al., 2013) & Individuals with a stroke & $\mathrm{S}, \mathrm{I}$ & Any & Pharmacological & Placebo & Disorders \\
\hline (Zahid et al., 2020) & Individuals with cancer & $\mathrm{S}, \mathrm{I}$ & Any & Any & $\mathrm{AC}, \mathrm{TAU}, \mathrm{WL}$ & $\begin{array}{l}\text { Symptoms, } \\
\text { disorders }\end{array}$ \\
\hline (Nigatu et al., 2019) & $\begin{array}{l}\text { Individuals with subthreshold } \\
\text { symptoms }\end{array}$ & I & Workplace & PS & TAU, WL & Symptoms \\
\hline (Cuijpers et al., 2014) & & I & Any & PT & AC, TAU, WL, & \\
\hline
\end{tabular}


Table 1 (continued)

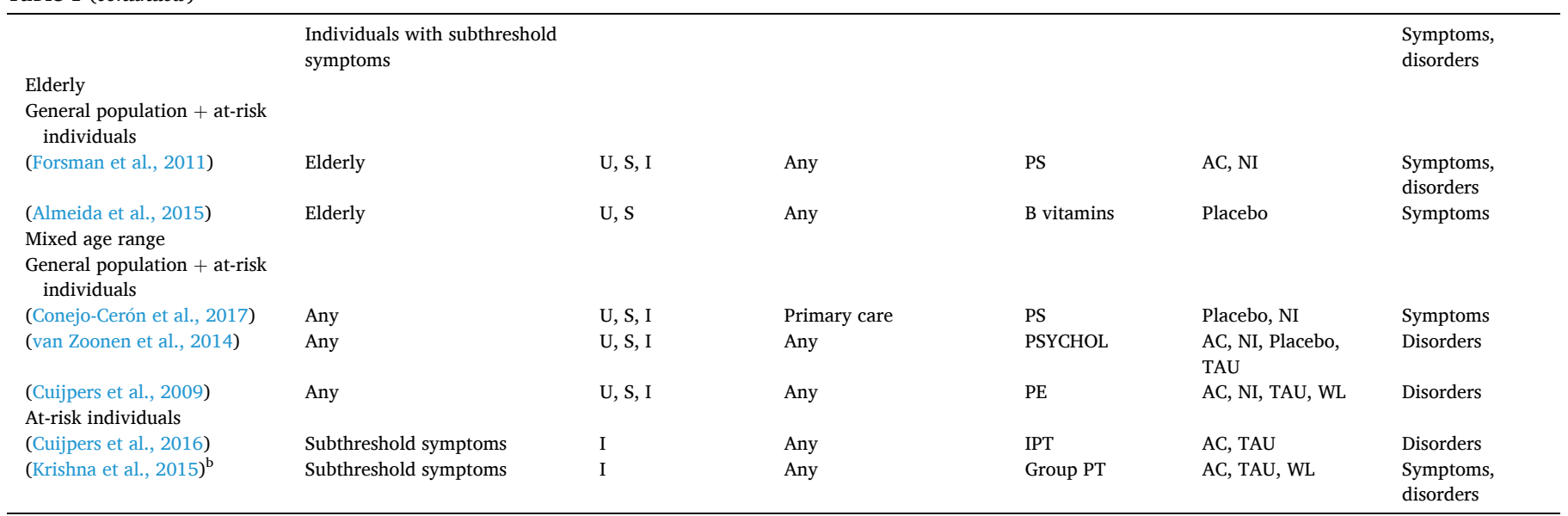

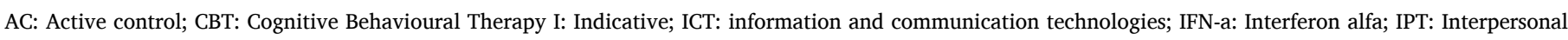

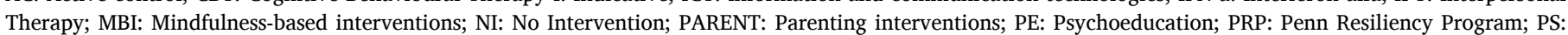

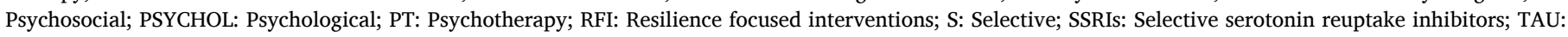
Treatment as usual; U: universal; WL: Waiting List.

and this over aggregate pairwise meta-analyses. The most recent study was selected when the previous criteria did not apply. If, after applying the hierarchical criteria, two studies were similar, both were included (Fusar-Poli et al., 2020).

\section{Data extraction}

Two researchers (JVS, AP) independently extracted data from all included studies into a database (a Microsoft Excel spreadsheet). A third author (GSP) cross-checked the data extraction. Summary of included variables included the following information: first author and year of publication, interventions, type of primary prevention (universal vs selective vs indicated, eTable 1), number of studies included in each metaanalysis, sample size, age, \% females, type of diagnostic assessment (clinical vs psychometric), comparison condition (active control vs no intervention vs placebo vs treatment as usual vs waiting list), outcome (symptoms vs disorders), randomization (required vs not required), quality assessment (see below), credibility (see below) and key findings. Interventions encompassed psychosocial interventions and pharmacological interventions.

\section{Data synthesis and effect measures}

We ran a systematic umbrella review of the key meta-analytical results from the included studies. Results were stratified by: (i) age range (prenatal/perinatal period - usually including adolescents and young adults - vs children and adolescents ( $\leq 19$ years) vs adults vs elderly ( $\geq 75$ years) vs mixed- including both adults and adolescents but excluding the prenatal/perinatal period-, (ii) target population (general population only vs at-risk individuals only vs general population + atrisk individuals) and (iii) type of intervention provided (see above). Atrisk individuals include individuals with risk factors for depression (selective approaches), individuals with subthreshold symptoms (indicated approaches), or both. Further sensitivity analyses were conducted within meta-analyses in which all studies were randomized controlled trials.

To summarize the meta-analytical evidence in the literature, we provided the median and largest effect size for each of the categories (iiii), selecting the most representative and comprehensive meta-analysis provided by each study, respecting the hierarchy of the evidence. For continuous data, all metrics were converted into Standardized Mean Difference (SMD) using Comprehensive Meta-Analysis (v3) (Borenstein et al., 2013) and Psychometrica (Lenhard and Lenhard, 2016).
Categorical data were all converted to risk ratio (RR). Whenever RR was not available, risk difference (RD) was extracted. To convert RD into RR, we then used the standard formula of the confidence interval of the RD to derive the number of events in the intervention and control arms (Hackshaw, 2009), and then used these estimated number of events to calculate the RR. To our knowledge, there is no standard method to convert RD into RR without knowing other information, such as the baseline risk. Odds ratio (OR) was converted into RR (Zhang and Yu, 1998), assuming a prevalence of depression of $12.9 \%$ in the general population (Lim et al., 2018). The significance level for effect sizes was set at alpha $=0.05$.

\section{Quality assessment and credibility criteria}

The quality of the included meta-analyses was assessed with the AMSTAR tool (Shea et al., 2009). AMSTAR is a reliable and valid measurement tool to assess the methodological quality of systematic reviews. AMSTAR assesses 11 items and provides a score from 0 (low quality) to 11 (high quality) (eMethods 2). As per protocol, to ensure adequate methodological quality evidence that could lead to appropriate executive summary recommendations, only studies in which $6-11 / 11(>50 \%)$ of the obtained scores were included in the review. Furthermore, AMSTAR-PLUS Content was used to evaluate the content and the potential biases of the included studies, using six quality items related to the blinding, sample size, sample size per arm, presence of observed case analyses, heterogeneity of the primary outcome and publication bias (range, 0-8) (Correll et al., 2017).

To identify the most credible interventions, we applied the following five criteria: i) p values $<0.005$; ii) sample size $>1000$; iii) largest study significant; iv) AMSTAR score $>75 \%$ total score (i.e., $>8 / 11$ ); v) AMSTAR-PLUS Content score $>75 \%$ total score (i.e. $\geq 6 / 8$ ) (Koletsi et al., 2020; Solmi et al., 2020c). Credibility was considered high if 5/5 credibility criteria were met, moderate if $4 / 5$ credibility criteria were met and insufficient or low if $\leq 3 / 5$ credibility criteria were met (Dragioti et al., 2019). All meta-analyses including at least one non-randomized clinical trial were considered as having low/insufficient credibility.

\section{Standards for guideline development}

To develop the recommendations, we followed the Preventive Services Task Force (USPSTF) grading system (U.S. Preventive Services Task Force, 2012) (eTable 3), which is suited explicitly for preventive 
approaches and has already received extensive validation (Addington et al., 2017; Curry et al., 2019; Fusar-Poli et al., 2020; Jemal et al., 2015). Guideline development reached consensus across the multi-disciplinary ECNP PMD-MHP Network.

\section{Results}

\section{Characteristics of the database}

The literature search yielded 8,042 records. After the exclusion of non-relevant titles or abstracts, 281 full-text articles were screened. Forty-six meta-analyses were finally included (Fig. 1), encompassing 928 individual studies and 286,429 total participants. The mean age of the individuals was 22.4 years (range from 10.7 years (Yap et al., 2016) to 77 years (Forsman et al., 2011)). 81.1\% individuals were female (range from 29\% females (Young et al., 2019) to 100\% females (Benzies et al., 2013; Carter et al., 2019; Cluxton-Keller and Bruce, 2018; Dennis and Dowswell, 2013; Dennis et al., 2008; Goodman et al., 2018; O'Connor et al., 2019)) (eTable 4).

Six (13.0\%) meta-analyses focused on the prenatal/perinatal period; $12(26.1 \%)$ on children and adolescents; $21(45.7 \%)$ on adults; two (5.3\%) on elderly; five $(10.9 \%)$ on mixed age ranges. The target population in seven (15.2\%) meta-analyses was the general population, in 16 (34.8\%) individuals at-risk [either for risk factors for depression (selective approaches), for subthreshold symptoms (indicated approaches), or for both)], and in $23(50 \%)$ both individuals in the general population and at risk for depression. The most frequently studied interventions were psychosocial interventions (77.8\%). Most (56.5\%) studies in the literature included a mixture of universal, selective and indicated interventions (eTable 1 (WHO, 2004)). These are reported in the Table 1 and in the supplementary material for each study (eTable 4). Narrative results by target population (general population, at-risk population, general population + at-risk population) can be found in eResults.

Table 2

Efficacy of preventive interventions for depression according age range, target population and type of intervention

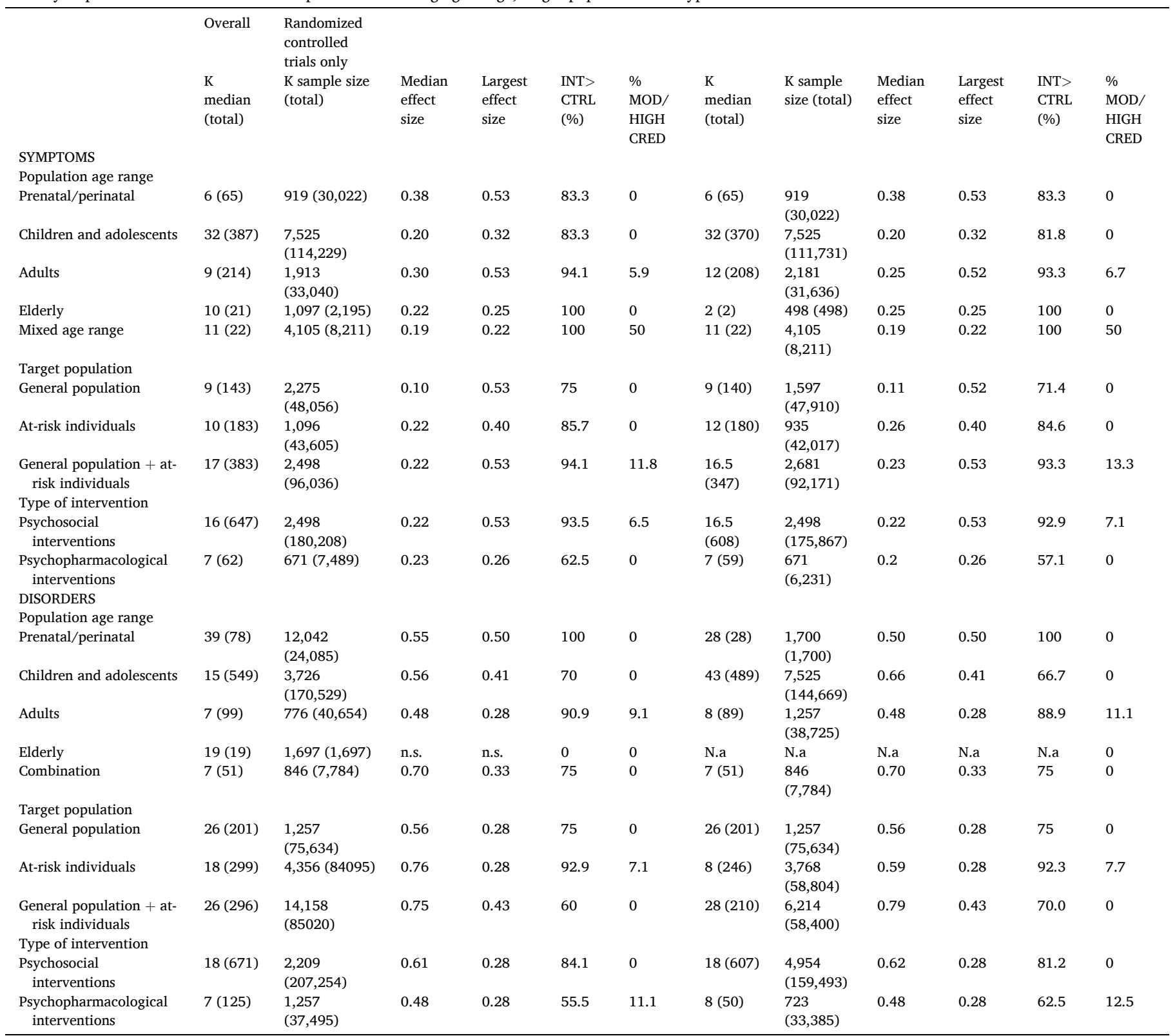

Cred: Credibility; Ctrl: Control; Int: Intervention; K: Number of individual studies; MOD: Moderate. 
Table 3

Preventive interventions focusing on individuals with a medical condition

\begin{tabular}{|c|c|c|c|c|c|}
\hline INTERVENTION & & $\begin{array}{c}\text { Post-test } \\
\text { (0-4 weeks) }\end{array}$ & $\begin{array}{l}\text { Short-term } \\
(<6 \text { months })\end{array}$ & $\begin{array}{l}\text { Long-term } \\
\text { ( } \geq 6 \text { months) }\end{array}$ & Credibility \\
\hline \multicolumn{6}{|c|}{ Hepatitis $C$ treated by interferon-alpha } \\
\hline \multirow[t]{3}{*}{ SSRIs } & Symptoms & N.s. & & & $0.5 / 5$ \\
\hline & & $\mathrm{SMD}=0.26$ & N.s. & N.s. & $0.5 / 5$ \\
\hline & Disorders & $\mathrm{RR}=0.56-0.59$ & & & $0.5 / 5$ \\
\hline \multicolumn{6}{|l|}{ Individuals with Cancer } \\
\hline \multirow[t]{2}{*}{ Pharmacological treatments ${ }^{\mathrm{a}}$} & Symptoms & & & & \\
\hline & Disorders & $\mathrm{RR}=0.34$ & & & $2 / 5$ \\
\hline \multirow[t]{2}{*}{ Psychosocial interventions } & Symptoms & $\mathrm{SMD}=0.23$ & & & $2 / 5$ \\
\hline & Disorders & & & & \\
\hline \multirow[t]{2}{*}{ Other interventions ${ }^{\mathrm{b}}$} & Symptoms & $\mathrm{SMD}=0.17$ & & & $2 / 5$ \\
\hline & Disorders & & & & \\
\hline \multicolumn{6}{|l|}{ Stroke } \\
\hline \multirow[t]{3}{*}{ Any pharmacological INT } & Symptoms & $\mathrm{SMD}=0.2$ & & & $3 / 5$ \\
\hline & Disorders & $\mathrm{RR}=0.37$ & & & $3 / 5$ \\
\hline & & & & $\mathrm{RR}=0.34$ & $3 / 5$ \\
\hline \multirow[t]{2}{*}{ SSRIs } & Symptoms & & & & \\
\hline & Disorders & $\mathrm{RR}=0.78$ & & & $5 / 5$ \\
\hline \multirow[t]{2}{*}{ Fluoxetine } & Symptoms & N.s. & & & $1 / 5$ \\
\hline & Disorders & $\mathrm{RR}=0.28$ & & & $1 / 5$ \\
\hline \multirow[t]{2}{*}{ Sertraline } & Symptoms & & & & \\
\hline & Disorders & $\mathrm{RR}=0.48$ & & & $3 / 5$ \\
\hline
\end{tabular}

SSRIs: selective serotonin reuptake inhibitors

a Melatonin, citalopram, escitalopram

b Exercise, physical therapies, support, meditation

\section{Umbrella review}

\section{Preventive interventions for depressive symptoms}

Considering all 39 (84.8\%) meta-analyses, 709 studies (median $\mathrm{k}=12$ ) and 187,697 individuals (median=1,632) that focused on depressive symptoms were included in the present work. The median effect size for any intervention was $\mathrm{SMD}=0.22$. The largest effect size was $\mathrm{SMD}=0.53 .87 .2 \%$ of the interventions had a significant effect size. Considering the $35(76.1 \%)$ meta-analyses including only randomized controlled trials (RCTs), 667 individual studies (median $\mathrm{k}=12$ ) and 182,098 individuals (median $n=1,544$ ) were included. The median effect size was $\mathrm{SMD}=0.21$. The largest effect size was $\mathrm{SMD}=0.53 .85 .7 \%$ of the interventions had a significant effect size (Table 2, eTable 4).

\section{Preventive interventions for depressive disorders}

Considering all 28 (60.9\%) meta-analyses, 796 studies (median $\mathrm{k}=15$ ) and 244,749 individuals (median $=2,181$ ) that focused on depressive disorders were included in the present work. The median effect size was $R R=0.54$. The largest effect size was $R R=0.28$. $75 \%$ interventions had a significant effect size. Considering the $24(52.2 \%)$ meta-analyses including only RCTs, 657 individual studies (median $\mathrm{k}=16$ ) and 192,878 individuals (median $\mathrm{n}=2,181$ ) were included. The median effect size was $\mathrm{RR}=0.54$. The largest effect size was $\mathrm{RR}=0.28$. $75 \%$ of interventions had a significant effect size (Table 2, eTable 4).

\section{Preventive interventions during the prenatal/perinatal period}

Considering all six (13.0\%) meta-analyses, those focusing on depressive symptoms included 65 individual studies (median $\mathrm{k}=6$ ) and 30,022 individuals (median $\mathrm{n}=919$ ). The median effect size was $\mathrm{SMD}=0.38$. The largest effect size was $\mathrm{SMD}=0.53$. $83.3 \%$ of interventions had a significant effect size. The two (4.3\%) meta-analyses focusing on depressive disorders included 78 individual studies (median $\mathrm{k}=39$ ) and 24,085 individuals (median $\mathrm{n}=12,042$ ). The median effect size was $R R=0.55$. The largest effect size was $R R=0.50 .100 \%$ of the interventions had a significant effect size (Table 2, Fig. 2)

Considering the six (13.0\%) meta-analyses including only RCTs, those focusing on depressive symptoms included 65 individual studies (median $\mathrm{k}=6$ ) and 30,022 individuals (median $\mathrm{n}=919$ ). The median effect size for preventive interventions for depressive symptoms in women in the prenatal/perinatal period was $\mathrm{SMD}=0.38$. The largest effect size was $\mathrm{SMD}=0.53 .83 .3 \%$ of interventions had a significant effect size. Only one meta-analysis including only RCTs focused on depressive disorders. It included 28 individual studies and 1,700 individuals. Its effect size was $R R=0.50$ (Table 2, Fig. 2).

\section{Preventive interventions for children and adolescents}

Considering all 12 (26.1\%) meta-analyses, those focusing on depressive symptoms as an outcome included 387 individual studies (median $\mathrm{k}=32$ ) and 114,229 individuals (median $\mathrm{n}=7,525$ ). The median effect size was $\mathrm{SMD}=0.2$. The largest effect size was $\mathrm{SMD}=0.32 .83 .3 \%$ of the interventions had a significant effect size. The 10 (21.7\%) metaanalyses focusing on depressive disorders as an outcome included 549 individual studies (median $\mathrm{k}=15$ ) and 170,529 individuals (median $\mathrm{n}=3,726$ ). The median effect size was $\mathrm{RR}=0.56$. The largest effect size was $R R=0.41 .70 \%$ of the interventions had a significant effect size (Table 2, Fig. 2).

Considering the 11 (23.9\%) meta-analyses including only RCTs, meta-analyses focusing on depressive symptoms as outcome included 370 individual studies (median $\mathrm{k}=72$ ) and 111,731 individuals (median $\mathrm{n}=7,525)$. The median effect size was $\mathrm{SMD}=0.20$. The largest effect size was $\mathrm{SMD}=0.32 .81 .8 \%$ of the interventions had a significant effect size. The nine $(19.6 \%)$ meta-analyses focusing on depressive disorders as outcome included 489 individual studies (median $\mathrm{k}=43$ ) and 144,669 individuals (median $n=7,525$ ). The median effect size was $R R=0.66$. The largest effect size was $R R=0.41 .66 .7 \%$ of the interventions had a significant effect size (Table 2, Fig. 2).

\section{Preventive interventions for adults}

Considering all 17 (37.0\%) meta-analyses, those focusing on depressive symptoms included 214 individual studies (median $\mathrm{k}=9$ ) and 33,040 individuals (median $\mathrm{n}=1,913$ ). The median effect size for preventive interventions for depressive symptoms in adults was $S M D=0.30$. The largest effect size was $\mathrm{SMD}=0.53$. $94.1 \%$ of interventions had a significant effect size. The $11(23.9 \%)$ meta-analyses focusing on depressive disorders included 99 individual studies (median $\mathrm{k}=7$ ) and 40,654 individuals (median $\mathrm{n}=776$ ). The median effect size was 

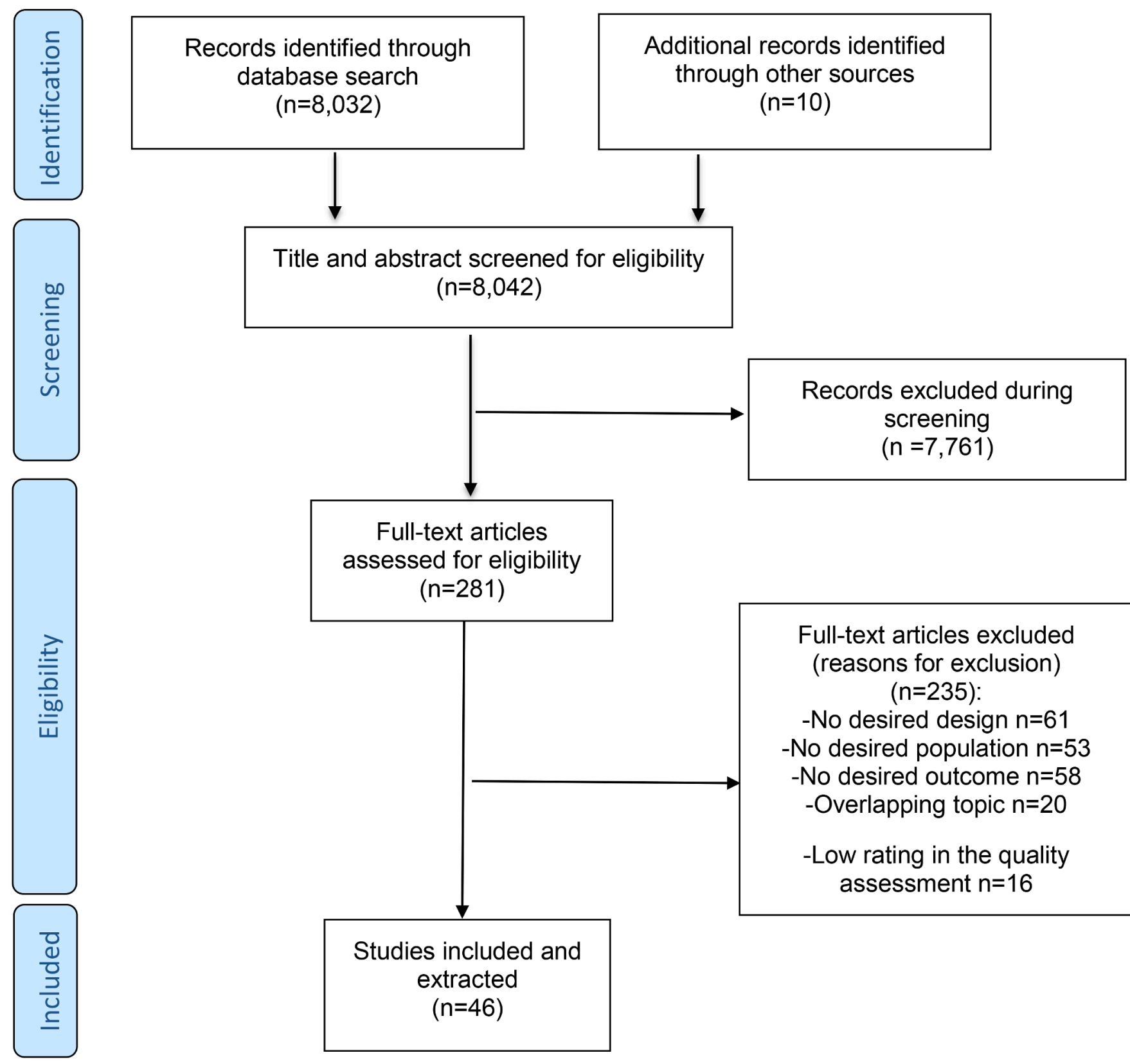

Fig. 1. Preferred Reporting Items for Systematic Reviews and Meta-analyses (PRISMA) flowchart outlining study selection process.

$\mathrm{RR}=0.48$. The largest effect size was $\mathrm{RR}=0.28$. $90.9 \%$ of the interventions had a significant effect size (Table 2, Fig. 2).

Considering the $15(32.6 \%)$ meta-analyses including only RCTs, those focusing on depressive symptoms included 208 individual studies (median $\mathrm{k}=12$ ) and 31,636 individuals (median $\mathrm{n}=2,181$ ). The median effect size for preventive interventions for depressive symptoms in adults was $\mathrm{SMD}=0.25$. The largest effect size was $\mathrm{SMD}=0.52 .93 .3 \%$ of the interventions had a significant effect size. The nine (19.6\%) metaanalyses focusing on depressive disorders included 89 individual studies (median $\mathrm{k}=8$ ) and 38,725 individuals (median $\mathrm{n}=1,257$ ). The median effect size was $R R=0.48$. The largest effect size was $R R=0.28$. $88.9 \%$ of the interventions had a significant effect size (Table 2, Fig. 2).

\section{Preventive interventions for the elderly}

Considering all two (4.3\%) meta-analyses, meta-analyses focusing on depressive symptoms included 21 individual studies (median $\mathrm{k}=10$ ) and 2,195 individuals (median $\mathrm{n}=1,097$ ). The median effect size was
$\mathrm{SMD}=0.22$. The largest effect size was $\mathrm{SMD}=0.25 .100 \%$ of interventions had a significant effect size. Only one meta-analysis focused on the prevention of depressive disorders. It included 19 individual studies and 1,697 individuals. Its results were not significant $(\mathrm{p}>0.05)$ (Table 2, Fig. 2)

Considering the meta-analyses including only RCTs, only one metaanalysis focused on the prevention of depressive symptoms. It included two individual studies and 498 individuals. Its effect size was $\mathrm{RR}=0.25$. No studies including only RCTs evaluated preventive interventions for depressive disorders in the elderly (Table 2, Fig. 2).

Preventive interventions for individuals with mixed age ranges

Considering all meta-analyses evaluating mixed age ranges (including both adults and adolescents but excluding the prenatal/ perinatal period), the two (4.3\%) meta-analyses focusing on depressive symptoms included 22 individual studies (median $\mathrm{k}=11$ ) and 8,211 individuals (median $\mathrm{n}=4,105$ ). The median effect size was $\mathrm{SMD}=0.19$. 
Table 4

Executive summary: Relevant ECNP PMD-MHP Network recommendations for the prevention of depression

\begin{tabular}{|c|c|c|}
\hline Stage & Intervention & Recommendation \\
\hline \multirow[t]{2}{*}{$\begin{array}{l}\text { Prenatal/ } \\
\text { perinatal } \\
\text { period }\end{array}$} & $\begin{array}{l}\text { Psychopharmacological } \\
\text { treatments }\end{array}$ & $\begin{array}{l}\text { Grade I: Current evidence is } \\
\text { insufficient to determine the } \\
\text { balance of benefits and harms for } \\
\text { these interventions. }\end{array}$ \\
\hline & Psychosocial interventions & $\begin{array}{l}\text { Grade C: Current evidence suggests } \\
\text { that psychosocial interventions } \\
\text { (psychoeducation or psychological } \\
\text { interventions }{ }^{\mathrm{a}} \text { ) should be offered to } \\
\text { selected pregnant women or during } \\
\text { the peripartum period, depending } \\
\text { on individual circumstances and } \\
\text { based on professional judgment } \\
\text { and patient preferences and values. }\end{array}$ \\
\hline \multirow[t]{2}{*}{$\begin{array}{l}\text { Children and } \\
\text { adolescents }\end{array}$} & $\begin{array}{l}\text { Psychopharmacological } \\
\text { treatments }\end{array}$ & $\begin{array}{l}\text { Grade I: Current evidence is } \\
\text { insufficient to determine the } \\
\text { balance of benefits and harms for } \\
\text { these interventions. }\end{array}$ \\
\hline & Psychosocial interventions & $\begin{array}{l}\text { Grade C: Current evidence suggests } \\
\text { that psychosocial interventions } \\
\text { (psychoeducation or psychological } \\
\text { interventions }{ }^{\mathrm{a}} \text { ) should be offered to } \\
\text { selected children and adolescents } \\
\text { depending on individual } \\
\text { circumstances and based on } \\
\text { professional judgment and patient } \\
\text { preferences and values. }\end{array}$ \\
\hline \multirow[t]{2}{*}{ Adults } & $\begin{array}{l}\text { Psychopharmacological } \\
\text { treatments }\end{array}$ & $\begin{array}{l}\text { Grade B-C: Current evidence } \\
\text { suggests that SSRIs should be } \\
\text { offered to selected individuals who } \\
\text { have suffered a stroke, depending } \\
\text { on individual circumstances and } \\
\text { based on professional judgment } \\
\text { regarding safety and patient } \\
\text { preferences and values. }\end{array}$ \\
\hline & Psychosocial interventions & $\begin{array}{l}\text { Grade C: Current evidence suggests } \\
\text { that psychosocial interventions } \\
\text { (psychoeducation or psychological } \\
\text { interventions }{ }^{\mathrm{a}} \text { ) should be offered to } \\
\text { selected individuals depending on } \\
\text { individual circumstances and based } \\
\text { on professional judgment and } \\
\text { patient preferences, particularly to } \\
\text { young adults. Psychosocial } \\
\text { interventions should be considered } \\
\text { after risks and benefits are balanced } \\
\text { in healthcare professionals and } \\
\text { individuals at risk. }\end{array}$ \\
\hline \multirow[t]{2}{*}{ Elderly } & $\begin{array}{l}\text { Psychopharmacological } \\
\text { treatments }\end{array}$ & $\begin{array}{l}\text { Grade I: Current evidence is } \\
\text { insufficient to determine the } \\
\text { balance of benefits and harms for } \\
\text { these interventions. }\end{array}$ \\
\hline & Psychosocial interventions & $\begin{array}{l}\text { Grade I: Current evidence is } \\
\text { insufficient to determine the } \\
\text { balance of benefits and harms for } \\
\text { these interventions. }\end{array}$ \\
\hline
\end{tabular}

a Among the psychological interventions, those improving psychological health and wellbeing, with a cognitive-behavioural orientation have the most robust evidence.

The largest effect size was $\mathrm{SMD}=0.22 .100 \%$ of the interventions had a significant effect size. The four (8.7\%) meta-analyses focusing on depressive disorders included 51 individual studies (median $\mathrm{k}=7$ ) and 7,784 individuals (median $\mathrm{n}=846$ ). The median effect was $\mathrm{RR}=0.70$. The largest effect size was $R R=0.33$. $75 \%$ of the interventions had a significant effect size (Table 2, Fig. 2)

Considering the two (4.6\%) meta-analyses including only RCTs, meta-analyses focusing on depressive symptoms included 22 individual studies (median $\mathrm{k}=11$ ) and 8,211 individuals (median $\mathrm{n}=4,105$ ). The median effect size was $\mathrm{SMD}=0.19$. The largest effect size was $\mathrm{SMD}=0.22 .100 \%$ of the interventions had a significant effect size. The four $(8.7 \%)$ meta-analyses focusing on depressive disorders included 51 individual studies (median $\mathrm{k}=7$ ) and 7,784 individuals (median $\mathrm{n}=846$ ). The median effect size was $R R=0.70$. The largest effect size was $\mathrm{RR}=0.33 .75 \%$ of the interventions had a significant effect size (Table 2, Fig. 2)

\section{Quality assessment and credibility assessment}

The quality of the 46 meta-analyses according to the AMSTAR was median $=9$, interquartile range $\mathrm{IQR}=8-9$, range from 6 to 11 (eTable 4). The quality of the included studies according to AMSTAR-PLUS Content median score was 4.25 (IQR=4-5), range from 2 to 6 .

Most meta-analyses $(43,93.5 \%)$ had insufficient or low credibility, mostly due to lack of double blinding in all the included studies (37, $80.4 \%$ ) or due to the largest study not being significant (32, 69.\%). Two meta-analyses (4.3\%) (Breedvelt et al., 2018; Conejo-Cerón et al., 2017), had moderate credibility and one (2.2\%) (Zhou et al., 2020) had high credibility according to our criteria. Reduction of depressive symptoms using psychosocial interventions for young adults (CBT, mindfulness, mind-body, or other approaches) (Breedvelt et al., 2018) and a combination of psychological and educational interventions in primary care had moderate credibility (Conejo-Cerón et al., 2017). Efficacy of preventive SSRIs in individuals who had suffered a stroke to prevent depressive disorders had high credibility (Zhou et al., 2020) (see eTable 5 and table 3 where preventive interventions focusing on individuals with a medical condition are presented).

\section{Discussion}

To our knowledge, this is the first comprehensive review summarizing the evidence obtained from previous meta-analyses evaluating primary preventive interventions for depression. We included 46 moderate- to high-quality meta-analyses encompassing 286,429 individuals. Overall, for depressive symptoms, $87.2 \%$ of the interventions were significantly superior to the control condition; for depressive disorder onset, $75 \%$ of the interventions were significantly superior to the control condition. Figures were slightly reduced to $85.7 \%$ for depressive symptoms when considering meta-analyses of RCTs only. Credibility was too low in most meta-analyses, mainly due to lack of double blinding in all the included studies or the largest study in the metaanalysis not being significant, to recommend their implementation. SSRIs to prevent depressive disorders in individuals with a stroke (Zhou et al., 2020) had the highest credibility. Psychosocial interventions for young adults (Breedvelt et al., 2018) and in primary care had moderate credibility (Conejo-Cerón et al., 2017).

Previous evidence suggested that preventive interventions delivered at an early age might have a particularly big impact on the prevention of depression onset (Gladstone et al., 2011). In children and adolescents, $83.3 \%$ of the interventions for depressive symptoms and $70 \%$ of the interventions for depressive disorders' onset were effective according to our results. However, none of the interventions had high credibility. All meta-analyses focused on psychosocial interventions in that age group, possibly due to concerns about the safety of antidepressants in children and adolescents, which in turn are driven by poor reporting and biased evidence as recently shown in a large-scale umbrella review on the safety of psychotropic medications in children and adolescents with mental disorders (Solmi et al., 2020a). Furthermore, it is common for clinical trials to exclude children and adolescents. Thus, current evidence is insufficient to assess the balance of benefits and harms for psychopharmacological medication (Grade I) (Table 4). However, antidepressant medication has shown to reduce relapse/recurrence of depression in children and adolescents who have already suffered a depressive episode (Cox et al., 2012). On the other hand, children and adolescents seem to be an appropriate target for preventive psychosocial interventions, particularly psychotherapeutic interventions, such as cognitive behavioural therapy (CBT) (Rasing et al., 2017), group-based CBT (Ssegonja et al., 2019) or metacognitive strategies (Kajka and 


\section{A) Population age range: symptoms (left), disorders (right)}
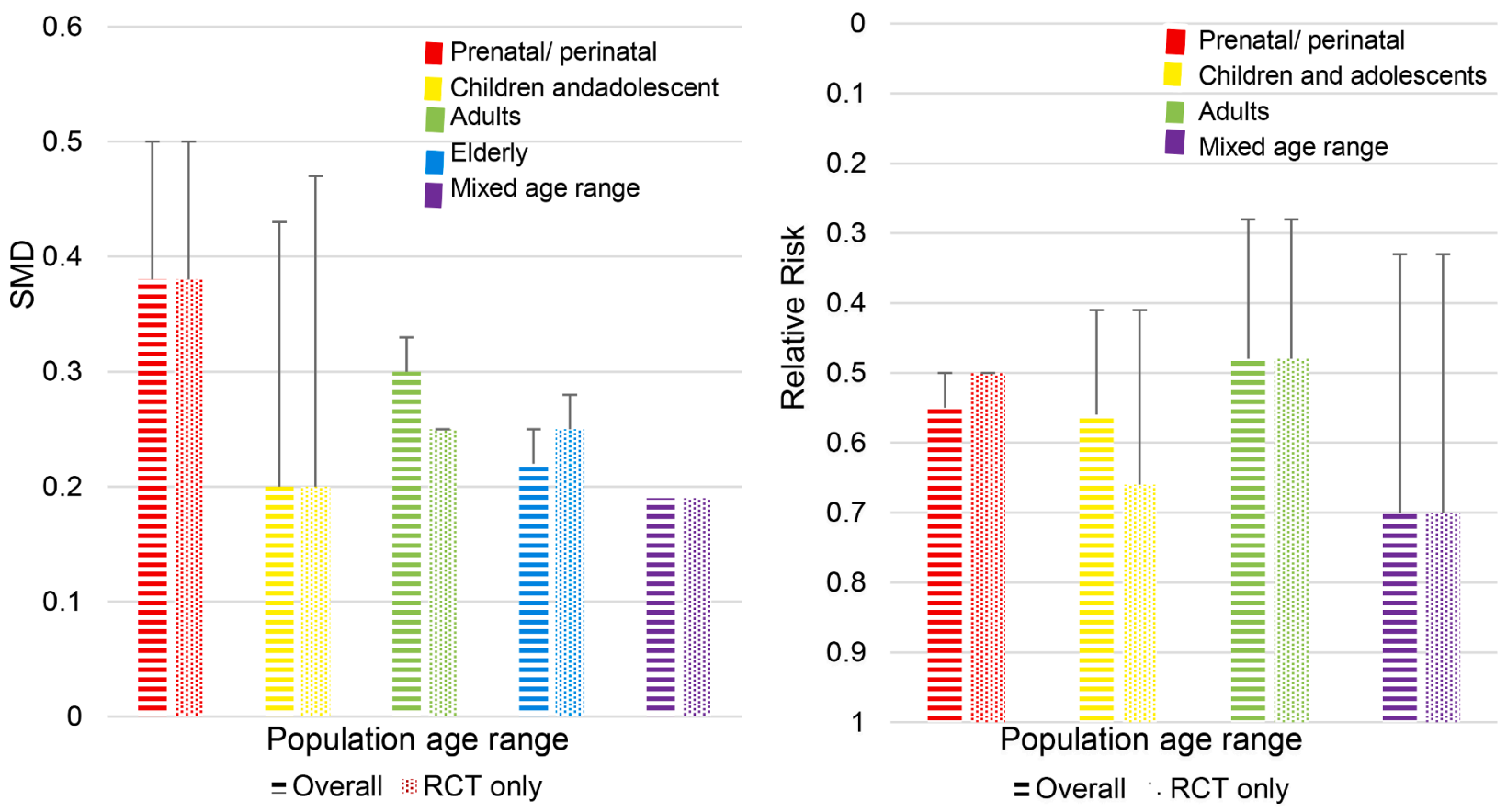

B) Target population: symptoms (left), disorders (right)
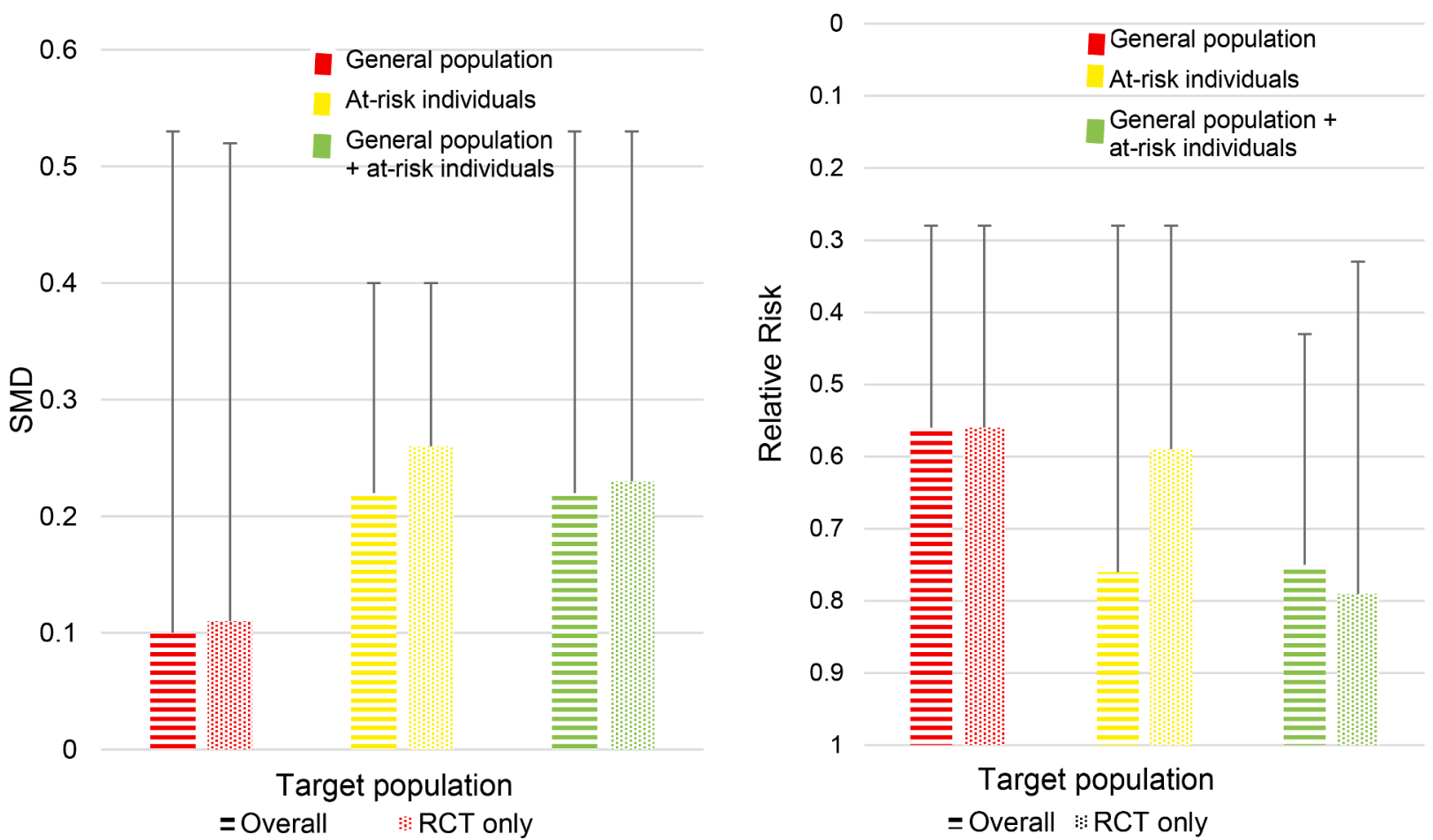

Fig. 2. Median and highest effect size stratified by population age range, target population and type of intervention (symptoms left, disorders right)

Kulik, 2021), conducted in school settings (Werner-Seidler et al., 2017). Although there seems to be more evidence for target-specific psychotherapeutic interventions (Hetrick et al., 2016) than other psychosocial interventions (e.g. parenting interventions) (Yap et al., 2016), the credibility of these interventions is not high enough to provide Grade A or Grade B recommendations. This finding is in line with meta-analytical evidence for the prevention of psychosis in children and adolescents (Catalan et al., 2020), where there is not enough evidence to recommend any one specific preventive intervention over the others. There is also not enough evidence for physical activity- which has overall shown 
C) Type of intervention: symptoms (left), disorders (right)
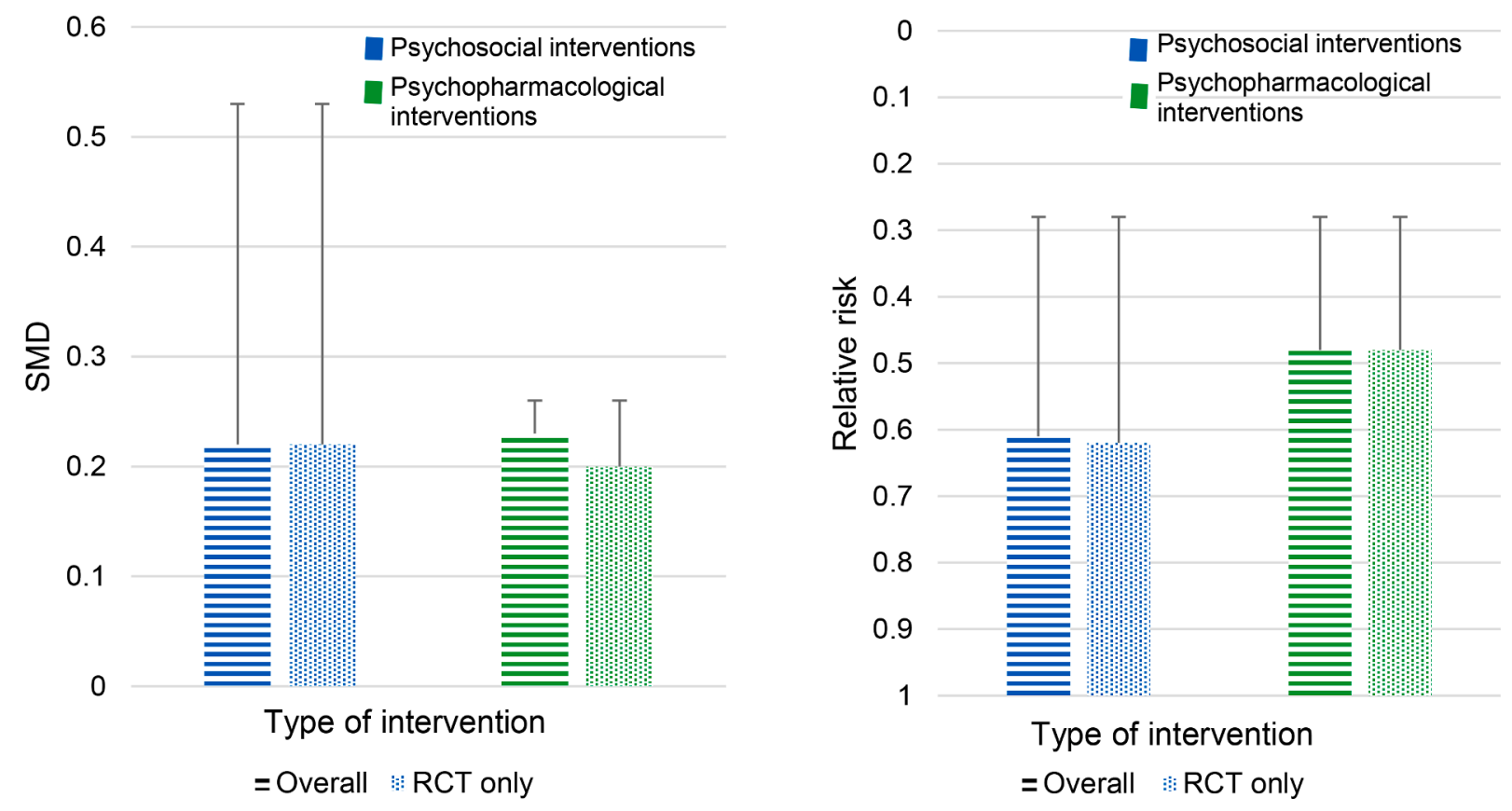

Fig. 2. (continued).

beneficial effects on physical and mental health (Ashdown-Franks et al., 2020; Murri et al., 2018)- to be recommended as a first-line intervention for the prevention of depression in those individuals at high risk for depression. However, physical activity may be a promising intervention to promote some good mental health core domains, particularly physical health (Fusar-Poli et al., 2019b). Further evidence about the efficacy of nutrition-based interventions is needed as well (Chopra et al., 2021). Stratifying by interventions focusing on the general population (universal approach) or at-risk populations only (targeted approach), median effect sizes were higher for at-risk populations for both depressive symptoms $(\mathrm{SMD}=0.22$ vs $\mathrm{SMD}=0.11)$ and depressive disorders $(\mathrm{RR}=0.73$ vs $\mathrm{RR}=0.56)$. Identifying individuals at-risk for depression in clinical services may be more challenging than identifying individuals at-risk for psychosis (Salazar de Pablo et al., 2021). These may include patients with subthreshold depressive symptoms (indicated approaches) or with risk factors for depression (selective approaches). For instance, individuals with adverse childhood life experiences might be particularly vulnerable to depression and thus susceptible to preventive approaches (Kuhn et al., 2016). Psychosocial interventions may be offered to at-risk children and adolescents depending on individual circumstances and based on professional judgment and patient preferences (Grade C).

In adults, who were the most frequently studied population, $94.1 \%$ of the interventions focusing on depressive symptoms and $90.9 \%$ of the interventions focusing on depressive disorder onset were effective. Regarding psychopharmacological treatments, risks outweigh benefits for individuals without a priori risk of developing depression. According to our umbrella review, psychopharmacological treatments may be considered in individuals with subthreshold symptoms (indicated interventions) and individuals with medical conditions (Table 3). Antidepressants have been used as preventive treatments for individuals with hepatitis C treated by interferon-alpha (Ehret and Sobieraj, 2014; Jiang et al., 2014), and for individuals with cancer (Zahid et al., 2020) (see Table 3). Furthermore, antidepressants reduced the incidence of depression ( $R R=0.33$ ) ( $\mathrm{Gu}$ et al., 2020)- particularly those with a treatment duration $\geq 1$ year $(R R=0.34)$ (Salter et al., 2013)- and improved symptoms of depression (SMD $=0.20$ ) (Gu et al., 2020) after an acute stroke. Under individual circumstances, professional judgment and patient preferences, antidepressants- preferably SSRIs due to the favourable adverse-effect profile- might be offered. However, according to current evidence, only the efficacy of preventive SSRIs to prevent depressive disorders in individuals who suffered a stroke was considered credible. A meta-analysis on the effect of preventive SSRIs in individuals with a stroke found side effects to be more common in SSRIs than placebo, including seizures $(R R=1.47)$ and nausea $(R R=3.07)$ (Zhou et al., 2020). However, other meta-analyses evaluating any SSRI (Mead et al., 2012) or sertraline in particular (Feng et al., 2018) did not find significant differences between the intervention and the control group regarding side effects. Future research should try to advance knowledge in personalized medicine to try to anticipate which individuals are more likely to suffer clinically relevant side effects (Kloiber et al., 2015). Meanwhile, SSRIs should be offered to individuals who have suffered a stroke, depending on individual circumstances and based on professional judgment regarding safety and patient preferences (Grade B-C evidence).

Overall, considering individual circumstances, professional judgment and patient preferences, psychosocial interventions including psychoeducation or psychological interventions as CBT and interpersonal therapy (IPT), may be offered to prevent depression in adults, particularly to young adults who are more likely to benefit from them (Grade C). However, psychosocial interventions for young adults (Breedvelt et al., 2018) and in primary care were the only interventions with moderate credibility (Conejo-Cerón et al., 2017), and there were no interventions with high credibility. Among individuals without a priori high risk of depression, interventions in the workplace setting prevented new cases of depression (Bellón et al., 2019). Psychosocial interventions in physicians had the largest effect size (Petrie et al., 2019). This finding, along with previous evidence, especially during pandemic periods, confirms that healthcare workers are an essential and fragile population (Arango, 2020; Salazar de Pablo et al., 2020b) and makes them a target population for preventive approaches, especially psychoeducation programs (Salazar de Pablo et al., 2020b). 
The incidence of postpartum depression is $12 \%$, and the overall prevalence of depression is $17 \%$ in healthy mothers without a prior history of depression (Shorey et al., 2018). This fact makes the prenatal/perinatal period an important period to consider implementing preventive approaches. The largest umbrella review of meta-analyses of observational evidence on the safety of antidepressants to date has shown that most of the claimed adverse events in pregnant women and their offspring taking antidepressants is actually driven by confounding by indication, as most meta-analyses have compared pregnant women/their offspring on antidepressants vs the general population, which was for the vast majority not affected by depression (Dragioti et al., 2019). However, there is no meta-analysis of pharmacological interventions during the prenatal/perinatal period to prevent depression. Furthermore, it will be challenging to implement RCTs in this population and the risk-benefit ratio may have to be evaluated using data from observational studies or registry data. In any case, current evidence is insufficient to assess the balance of benefits and harms of pharmacological interventions during the prenatal/perinatal period to prevent depression at the moment (Grade I). Regarding psychosocial interventions, current evidence suggests that they can be offered to pregnant women (Grade C). Pregnant women have shown a significant improvement after receiving psychosocial interventions for depressive symptoms (Goodman et al., 2018), as well as for the prevention of depressive disorders, including CBT (O'Connor et al., 2019) and IPT (O'Connor et al., 2019). Besides, preventive interventions seem to be as effective as interventions initiated after depression onset in the prenatal/perinatal period (Goodman et al., 2018). Universal exercise-based interventions also reduced depressive symptoms $(\mathrm{SMD}=0.52)$ (Carter et al., 2019). Thus, exercise-based interventions could be suitable for pregnant women without a particularly high risk for depression, while psychotherapy could be offered to high-risk pregnant women. Finally, there is not enough evidence to formulate definite recommendations regarding preventive approaches for the elderly (Grade I).

One of the main clinical implications of the primary prevention of depression is that it can have an influence not only on the onset of depression, but also on future recurrences (Ten Have et al., 2018) and on the attenuation of poor outcomes in the medium and long-term (Solmi et al., 2020b). For instance, early interventions to enhance resilience may be useful to prevent poor mental health outcomes (Ollmann et al., 2020). Furthermore, they could also have an impact on the future onset of mental disorders, including different types of mental disorders, which may start with subthreshold depressive symptoms, frequently in individuals with previous risk factors (Oliver et al., 2019). In psychotic disorders, depressive symptoms may mark the onset of the psychosis prodrome and be particularly relevant for their prognosis (Fusar-Poli et al., 2014). Individuals with attenuated psychosis syndrome (APS) also frequently suffered from comorbid depressive disorders preceding APS (Salazar de Pablo et al., 2019). Regarding other affective disorders, such as bipolar disorder, subthreshold symptoms and anxiety symptoms frequently appear before the first manic or depressive episode (Noto et al., 2015; Vieta et al., 2018). In fact, delays prior to the first treatment in bipolar disorder have been associated with more prolonged and more severe depressive phases, more comorbid conditions, and less time free of symptoms (Birmaher et al., 2006). Other mental disorders, such as substance use disorders, also have poorer prognosis if comorbid depressive disorders are present (Najt et al., 2011). Thus, the prevention of the first episode of depression is important for the prognosis of other mental disorders as well (Salazar de Pablo et al., 2020a).

However, primary preventive interventions face several challenges. One of the main challenges is poor adherence to the interventions offered by professionals. Not having an established mental disorder, it may be difficult for individuals, particularly for those with younger age, medical comorbidities, personality disorders, cognitive impairment or substance use disorders, to adhere to the preventive treatments (Solmi et al., 2020b). Multi-disciplinary and low-threshold interventions, including psychoeducation and behavioural interventions, including digital interventions, may help overcome this challenge (Solmi et al., 2020b). Another significant challenge for the establishment of preventive measures is the associated cost, especially for face-to-face interventions (Deady et al., 2017). Focusing on high-risk populations for some of the interventions only (Bellón et al., 2015) and promoting artificial intelligence-driven telemedicine interventions (Nair et al., 2018) have the potential to address difficult-to-reach, vulnerable populations while decreasing the cost of the interventions. However, early mental health interventions are usually cost-effective for the individuals and society, as they improve long-term outcomes and reduce the long-term adverse personal and economic consequences of poor mental health (Arango et al., 2018).

The results of this study must be interpreted within its limitations. First, meta-analyses of the prevention of depression often combined universal and targeted, i.e. selective, and indicated interventions in the same analyses (Ahlen et al., 2015). This heterogeneity is an intrinsic limitation of the underlying research, which we have considered when providing our recommendations. Second, meta-analyses of the prevention of depression often included both non-randomized and randomized clinical trials. To address this issue, we have reported estimates including meta-analyses that only considered randomized controlled trials separately, finding mostly consistent results. Third, most meta-analyses did not provide data on the long-term efficacy of preventive interventions. Future research should evaluate the persistence and long-term efficacy of preventive interventions and innovative delivery formats, such as internet-based therapies and smartphone-based interventions (Patoz et al., 2021). Fourth, most meta-analyses included no intervention, waiting list placebo and non-active interventions as the comparison condition. Thus, we could not establish grade A high level of certainty USPSTF recommendations for any specific preventive intervention, as we could not clearly demonstrate its effectiveness over the others. Future research should disentangle which particular interventions would be the most effective for each of the evaluated populations. Fifth, the results from the individual studies were not re-analysed for the present work. We converted the effect sizes provided to homogeneous comparable measures and reported median and largest effect size for each of the categories established. Sixth, although the quality of the conducted meta-analyses was moderate to high as the AMSTAR results showed, the included studies had frequently biases that affected the credibility of the evidence, as the AMSTAR-Plus content results showed. Seventh, our umbrella review addressed the efficacy but not the safety or tolerability of the interventions, which future work might consider, although primary studies, especially of psychosocial interventions, should also report more on potential risks of the interventions. Finally, as mentioned earlier, the conversion from RD to RR is an approximation, and thus, it should be interpreted with some caution.

\section{Conclusions}

Primary preventive interventions for depression can be effective, particularly for individuals with risk factors. Among them, clinicians may offer SSRIs for individuals post-stroke to prevent depressive disorders and psychosocial interventions for children, adolescents, young adults and during the prenatal/perinatal period, based on professional judgment and patient preferences and values. The credibility for most interventions is low at the moment to recommend their systematic implementation, indicating that more research is needed for whichgiven the relevance of this topic-adequate funding should be provided.

\section{Declaration of Competing Interest}

GSP has received honoraria from Janssen Cilag. CUC has been a consultant and/or advisor to or has received honoraria from Alkermes, Allergan, Angelini, Boehringer-Ingelheim, Gedeon Richter, Gerson Lehrman Group, Indivior, IntraCellular Therapies, Janssen/J\&J, LB 
Pharma, Lundbeck, MedAvante-ProPhase, Medscape, Merck, Neurocrine, Noven, Otsuka, Pfizer, Recordati, Rovi, Servier, Sumitomo Dainippon, Sunovion, Supernus, Takeda, and Teva. He has provided expert testimony for Bristol-Myers Squibb, Janssen, and Otsuka. He served on a Data Safety Monitoring Board for Boehringer-Ingelheim, Lundbeck, Rovi, Supernus, and Teva. He received royalties from UpToDate and grant support from Janssen and Takeda. He is also a shareholder of LB Pharma. SB acknowledges support from the University of Basel, the European Union's Seventh Framework Programme, the Swiss National Science Foundation and the ERA-NET. SB has received educational funds from Sunovion, Otsuka, Recordati, Servier, Janssen and Lundbeck. SG has been consultant or has received honoraria or grants from Millennium Pharmaceuticals; Innova Pharma - Recordati Group; Janssen Pharmaceutica, Sunovion Pharmarmaceuticals, Janssen-Cilag Polska; Gedeon Richter; Pierre Fabre; Otsuka and Angelini. AB received unrestricted scientific grants of the German Research Foundation (DFG), The German Ministry for Education and Research (BMBF) and Janssen; further speaker and travel grants were provided from Otsuka, Lundbeck and Janssen. LVK has within recent three years been a consultant for Lundbeck and Teva. CA has been a consultant to or has received honoraria or grants from Acadia, Angelini, Gedeon Richter, Janssen Cilag, Lundbeck, Otsuka, Roche, Sage, Servier, Shire, Schering Plough, Sumitomo Dainippon Pharma, Sunovion and Takeda. PFP has been a consultant to and received research funds from Lundbeck and received honoraria from Menarini.

\section{Author statement contributors}

GSP, MS and PFP conceived the study. GSP, JVS, AP and PM obtained the data. GSP conducted the analyses and wrote the first draft of the manuscript. GSP, MS and PFP worked on subsequent versions of the manuscript. All the authors revised the manuscript and PROVIDED a substantial conceptual contribution. All authors proofread and approved the final draft of the manuscript. GSP had full access to the study and takes responsibility for the manuscript

\section{Conflicts of Interest}

GSP has received honoraria from Janssen Cilag. CUC has been a consultant and/or advisor to or has received honoraria from Alkermes, Allergan, Angelini, Boehringer-Ingelheim, Gedeon Richter, Gerson Lehrman Group, Indivior, IntraCellular Therapies, Janssen/J\&J, LB Pharma, Lundbeck, MedAvante-ProPhase, Medscape, Merck, Neurocrine, Noven, Otsuka, Pfizer, Recordati, Rovi, Servier, Sumitomo Dainippon, Sunovion, Supernus, Takeda, and Teva. He has provided expert testimony for Bristol-Myers Squibb, Janssen, and Otsuka. He served on a Data Safety Monitoring Board for Boehringer-Ingelheim, Lundbeck, Rovi, Supernus, and Teva. He received royalties from UpToDate and grant support from Janssen and Takeda. He is also a shareholder of LB Pharma. SB acknowledges support from the University of Basel, the European Union's Seventh Framework Programme, the Swiss National Science Foundation and the ERA-NET. SB has received educational funds from Sunovion, Otsuka, Recordati, Servier, Janssen and Lundbeck. SG has been consultant or has received honoraria or grants from Millennium Pharmaceuticals; Innova Pharma - Recordati Group; Janssen Pharmaceutica, Sunovion Pharmarmaceuticals, Janssen-Cilag Polska; Gedeon Richter; Pierre Fabre; Otsuka and Angelini. AB received unrestricted scientific grants of the German Research Foundation (DFG), The German Ministry for Education and Research (BMBF) and Janssen; further speaker and travel grants were provided from Otsuka, Lundbeck and Janssen. LVK has within recent three years been a consultant for Lundbeck and Teva. EV has received grants and served as consultant, advisor or CME speaker for the following entities (unrelated to the present work): AB-Biotics, Abbvie, Aimentia, Angelini, Celon, Dainippon Sumitomo Pharma, Ferrer, Gedeon Richter, GH Research, Glaxo Smith-Kline, Janssen, Lundbeck, Organon, Otsuka, Sage, Sanofi-Aventis,
Sunovion, and Takeda. CA has been a consultant to or has received honoraria or grants from Acadia, Angelini, Gedeon Richter, Janssen Cilag, Lundbeck, Otsuka, Roche, Sage, Servier, Shire, Schering Plough, Sumitomo Dainippon Pharma, Sunovion and Takeda. PFP has been a consultant to and received research funds from Lundbeck and received honoraria from Menarini.

Supplementary Material

Supplementary data will be available online

\section{Funding Sources}

The study was supported by the European College of Neuropsychopharmacology Network Taskforce. GSP is supported by the Alicia Koplowitz Foundation. CA is supported by the Spanish Ministry of Science, Innovation, and Universties, Instituto de Salud Carlos III, European Regional Development Fund 'A way of making Europe,' Centro de Investigacion Biomedica en Red Salud Mental, Madrid Regional Government; and Fundación Mutua Madrileña

\section{Acknowledgment}

The authors declare that there are no conflicts of interest in relation to the subject of this study.

\section{Supplementary materials}

Supplementary material associated with this article can be found, in the online version, at doi:10.1016/j.jad.2021.07.101.

\section{References}

Addington, J., Devoe, D., Piskulic, D., Romanowska, S., Townes, P., 2017. Interventions and Cognitive Outcomes in Youth at Risk of Psychosis: A Systematic Review and Meta-Analysis. Neuropsychopharmacology 42, S591-S592.

Ahlen, J., Lenhard, F., Ghaderi, A., 2015. Universal Prevention for Anxiety and Depressive Symptoms in Children: A Meta-analysis of Randomized and ClusterRandomized Trials. J Prim Prev 36, 387-403.

Almeida, O.P., Ford, A.H., Flicker, L., 2015. Systematic review and meta-analysis of randomized placebo-controlled trials of folate and vitamin B12 for depression. Int. Psychogeriatr. 27, 727-737.

American Psychiatric Association, 2013. Diagnostic and statistical manual of mental disorders. Washington DC.

Arango, C., 2020. Lessons learned from the coronavirus health crisis in Madrid, Spain: How COVID-19 has changed our lives in the last two weeks. Biological Psychiatry.

Arango, C., Díaz-Caneja, C.M., McGorry, P.D., Rapoport, J., Sommer, I.E., Vorstman, J. A., McDaid, D., Marín, O., Serrano-Drozdowskyj, E., Freedman, R., Carpenter, W. 2018. Preventive strategies for mental health. Lancet Psychiatry 5, 591-604.

Ashdown-Franks, G., Firth, J., Carney, R., Carvalho, A.F., Hallgren, M., Koyanagi, A., Rosenbaum, S., Schuch, F.B., Smith, L., Solmi, M., Vancampfort, D., Stubbs, B., 2020. Exercise as Medicine for Mental and Substance Use Disorders: A Meta-review of the Benefits for Neuropsychiatric and Cognitive Outcomes. Sports Med. 50, 151-170.

Bastounis, A., Callaghan, P., Banerjee, A., Michail, M., 2016. The effectiveness of the Penn Resiliency Programme (PRP) and its adapted versions in reducing depression and anxiety and improving explanatory style: A systematic review and metaanalysis. J. Adolesc. 52, 37-48.

Bellón, J., Conejo-Cerón, S., Cortés-Abela, C., Pena-Andreu, J.M., García-Rodríguez, A., Moreno-Peral, P., 2019. Effectiveness of psychological and educational interventions for the prevention of depression in the workplace: A systematic review and metaanalysis. Scand. J. Work Environ. Health 45, 324-332.

Bellón, J., Moreno-Peral, P., Motrico, E., Rodríguez-Morejón, A., Fernández, A., SerranoBlanco, A., Zabaleta-del-Olmo, E., Conejo-Cerón, S., 2015. Effectiveness of psychological and/or educational interventions to prevent the onset of episodes of depression: A systematic review of systematic reviews and meta-analyses. Prev. Med. 76, S22-S32. Suppl.

Benzies, K.M., Magill-Evans, J.E., Hayden, K.A., Ballantyne, M., 2013. Key components of early intervention programs for preterm infants and their parents: a systematic review and meta-analysis. Bmc Pregnancy and Childbirth 13.

Birmaher, B., Axelson, D., Strober, M., Gill, M.K., Valeri, S., Chiappetta, L., Ryan, N., Leonard, H., Hunt, J., Iyengar, S., Keller, M., 2006. Clinical course of children and adolescents with bipolar spectrum disorders. Arch. Gen. Psychiatry 63, 175-183.

Borenstein, M., Hedges, L., Higgins, J., Rothstein, H., 2013. Comprehensive MetaAnalysis Version 3. Biostat, Englewood, NJ.

Breedvelt, J.J.F., Kandola, A., Kousoulis, A.A., Brouwer, M.E., Karyotaki, E., Bockting, C. L.H., Cuijpers, P., 2018. What are the effects of preventative interventions on major depressive disorder (MDD) in young adults? A systematic review and meta-analysis of randomized controlled trials. J. Affect. Disord. 239, 18-29. 
Brunwasser, S.M., Gillham, J.E., Kim, E.S., 2009. A meta-analytic review of the Penn Resiliency Program's effect on depressive symptoms. J. Consult. Clin. Psychol. 77, 1042-1054.

Carter, T., Bastounis, A., Guo, B., Jane Morrell, C., 2019. The effectiveness of exercisebased interventions for preventing or treating postpartum depression: a systematic review and meta-analysis. Arch Womens Ment Health 22, 37-53.

Catalan, A., Salazar de Pablo, G., Vaquerizo-Serrano, J., Mosillo, P., Fernández-Rivas, A., Arango, C., Moreno, C., Correll, C.U., Fusar-Poli, P., 2020. Prevention of psychosis in children and adolescents: advances in diagnosis, prognosis and treatment. JCPP, In press.

Chen, Y., Yang, K., Marušic, A., Qaseem, A., Meerpohl, J.J., Flottorp, S., Akl, E.A., Schünemann, H.J., Chan, E.S., Falck-Ytter, Y., Ahmed, F., Barber, S., Chen, C., Zhang, M., Xu, B., Tian, J., Song, F., Shang, H., Tang, K., Wang, Q., Norris, S.L., Group, R.R.I.f.P.G.i.H.W., 2017. A Reporting Tool for Practice Guidelines in Health Care: The RIGHT Statement. Ann. Intern. Med. 166, 128-132.

Chopra, C., Mandalika, S., Kinger, N., 2021. Does diet play a role in the prevention and management of depression among adolescents? A narrative review. Nutr Health, 260106020980532.

Cluxton-Keller, F., Bruce, M.L., 2018. Clinical effectiveness of family therapeutic interventions in the prevention and treatment of perinatal depression: A systematic review and meta-analysis. PLoS One 13.

Conejo-Cerón, S., Moreno-Peral, P., Rodríguez-Morejón, A., Motrico, E., NavasCampaña, D., Rigabert, A., Martín-Pérez, C., Rodríguez-Bayón, A., BallestaRodríguez, M.I., Luna, J.D., García-Campayo, J., Roca, M., Bellón, J., 2017. Effectiveness of Psychological and Educational Interventions to Prevent Depression in Primary Care: A Systematic Review and Meta-Analysis. Ann. Fam. Med. 15, 262-271.

Correll, C.U., Rubio, J.M., Inczedy-Farkas, G., Birnbaum, M.L., Kane, J.M., Leucht, S., 2017. Efficacy of 42 Pharmacologic Cotreatment Strategies Added to Antipsychotic Monotherapy in Schizophrenia: Systematic Overview and Quality Appraisal of the Meta-analytic Evidence. JAMA Psychiatry 74, 675-684.

Cox, G.R., Fisher, C.A., De Silva, S., Phelan, M., Akinwale, O.P., Simmons, M.B., Hetrick, S.E., 2012. Interventions for preventing relapse and recurrence of a depressive disorder in children and adolescents. Cochrane Database Syst. Rev. 11. CD007504.

Cuijpers, P., Donker, T., Weissman, M.M., Ravitz, P., Cristea, I.A., 2016. Interpersonal Psychotherapy for Mental Health Problems: A Comprehensive Meta-Analysis. American Journal of Psychiatry 173, 680-687.

Cuijpers, P., Koole, S.L., van Dijke, A., Roca, M., Li, J., Reynolds, C.F., 2014. Psychotherapy for subclinical depression: meta-analysis. British Journal of Psychiatry 205, 268.

Cuijpers, P., Muñoz, R.F., Clarke, G.N., Lewinsohn, P.M., 2009. Psychoeducational treatment and prevention of depression: the "Coping with Depression" course thirty years later. Clin. Psychol. Rev. 29, 449-458.

Curry, S.J., Krist, A.H., Owens, D.K., Barry, M.J., Caughey, A.B., Davidson, K.W., Doubeni, C.A., Epling, J.W., Kemper, A.R., Kubik, M., Landefeld, C.S., Mangione, C. M., Silverstein, M., Simon, M.A., Tseng, C.W., Wong, J.B., Force, U.P.S.T., 2019. Ocular Prophylaxis for Gonococcal Ophthalmia Neonatorum: US Preventive Services Task Force Reaffirmation Recommendation Statement. JAMA 321, 394-398.

Davies, E.B., Morriss, R., Glazebrook, C., 2014. Computer-Delivered and Web-Based Interventions to Improve Depression, Anxiety, and Psychological Well-Being of University Students: A Systematic Review and Meta-Analysis. Journal of Medical Internet Research 16, 18-39.

Deady, M., Choi, I., Calvo, R.A., Glozier, N., Christensen, H., Harvey, S.B., 2017. eHealth interventions for the prevention of depression and anxiety in the general population: a systematic review and meta-analysis. BMC Psychiatry 17, 310.

Deane, K.H.O., Jimoh, O.F., Biswas, P., O’Brien, A., Hanson, S., Abdelhamid, A.S. Fox, C., Hooper, L., 2019. Omega-3 and polyunsaturated fat for prevention of depression and anxiety symptoms: systematic review and meta-analysis of randomised trials. Br. J. Psychiatry 1-8.

Dennis, C.L., Dowswell, T., 2013. Psychosocial and psychological interventions for preventing postpartum depression. Cochrane Database of Systematic Reviews.

Dennis, C.L., Ross, L.E., Herxheimer, A., 2008. Oestrogens and progestins for preventing and treating postpartum depression. Cochrane Database Syst. Rev. CD001690.

Dragioti, E., Solmi, M., Favaro, A., Fusar-Poli, P., Dazzan, P., Thompson, T., Stubbs, B., Firth, J., Fornaro, M., Tsartsalis, D., Carvalho, A.F., Vieta, E., McGuire, P., Young, A. H., Shin, J.I., Correll, C.U., Evangelou, E., 2019. Association of Antidepressant Use With Adverse Health Outcomes: A Systematic Umbrella Review. JAMA Psychiatry 76, 1241-1255.

Dray, J., Bowman, J., Campbell, E., Freund, M., Wolfenden, L., Hodder, R.K., McElwaine, K., Tremain, D., Bartlem, K., Bailey, J., Small, T., Palazzi, K., Oldmeadow, C., Wiggers, J., 2017. Systematic Review of Universal ResilienceFocused Interventions Targeting Child and Adolescent Mental Health in the School Setting. Journal of the American Academy of Child and Adolescent Psychiatry 56, 813-824.

ECNP, 2019. European College of NeuroPsychopharmacology Thematic Working Group on the Prevention of Mental Disorders and Mental Health Promotion ECNP.

Ehret, M., Sobieraj, D.M., 2014. Prevention of interferon-alpha-associated depression with antidepressant medications in patients with hepatitis $C$ virus: a systematic review and meta-analysis. International Journal of Clinical Practice 68, 255-261.

Faggion, C.M., 2015. Critical appraisal of AMSTAR: challenges, limitations, and potential solutions from the perspective of an assessor. BMC Med. Res. Methodol. 15, 63.

Feng, R., Wang, P., Gao, C., Yang, J., Chen, Z., Yang, Y., Jiao, J., Li, M., Fu, B., Li, L., Zhang, Z., Wang, S., 2018. Effect of sertraline in the treatment and prevention of poststroke depression: A meta-analysis. Medicine (Baltimore). 97, e13453.
Forsman, A.K., Schierenbeck, I., Wahlbeck, K., 2011. Psychosocial interventions for the prevention of depression in older adults: systematic review and meta-analysis. J. Aging Health 23, 387-416.

Fusar-Poli, P., 2019. Integrated Mental Health Services for the Developmental Period (0 to 25 Years): A. Critical Review of the Evidence. Front Psychiatry 10, 355.

Fusar-Poli, P., Bauer, M., Borgwardt, S., Bechdolf, A., Correll, C.U., Do, K.Q. Domschke, K., Galderisi, S., Kessing, L.V., Koutsouleris, N., Krebs, M.O., Lennox, B., McGuire, P., Meyer-Lindenberg, A., Millan, M.J., Nieman, D., Pfennig, A., Sand, M., Whenert, A., van Amelsvoort, T., Arango, C., 2019a. European college of neuropsychopharmacology network on the prevention of mental disorders and mental health promotion (ECNP PMD-MHP). Eur. Neuropsychopharmacol. 29, 1301-1311.

Fusar-Poli, P., McGorry, P.D., Kane, J.M., 2017. Improving outcomes of first-episode psychosis: an overview. World Psychiatry 16, 251-265.

Fusar-Poli, P., Nelson, B., Valmaggia, L., Yung, A.R., McGuire, P.K., 2014. Comorbid Depressive and Anxiety Disorders in 509 Individuals With an At-Risk Mental State: Impact on Psychopathology and Transition to Psychosis. Schizophrenia Bulletin 40, $120-131$.

Fusar-Poli, P., Radua, J., 2018. Ten simple rules for conducting umbrella reviews. Evid. Based Ment. Health 21, 95-100.

Fusar-Poli, P., Salazar de Pablo, G., Correll, C.U., Meyer-Lindenberg, A., Millan, M.J., Borgwardt, S., Galderisi, S., Bechdolf, A., Pfennig, A., Kessing, L.V., van Amelsvoort, T., Nieman, D.H., Domschke, K., Krebs, M.O., Koutsouleris, N., McGuire, P., Do, K.Q., Arango, C., 2020. Prevention of Psychosis: Advances in Detection, Prognosis, and Intervention. JAMA Psychiatry.

Fusar-Poli, P., Salazar de Pablo, G., De Micheli, A., Nieman, D., Correll, C., Kessing, L.V., Pfennig, A., Bechdolf, A., Borgwardt, S., Arango, C., van Amelsvoort, T., $2019 \mathrm{~b}$. What is good mental health? A scoping review. European Neuropsychopharmacology.

Gladstone, T.R., Beardslee, W.R., O'Connor, E.E., 2011. The prevention of adolescent depression. Psychiatr. Clin. North Am. 34, 35-52.

Goodman, S.H., Cullum, K.A., Dimidjian, S., River, L.M., Kim, C.Y., 2018. Opening windows of opportunities: Evidence for interventions to prevent or treat depression in pregnant women being associated with changes in offspring's developmental trajectories of psychopathology risk. Development and Psychopathology 30, 1179-1196.

Gu, J., Huang, H., Chen, K., Huang, G., Huang, Y., Xu, H., 2020. Are they necessary? Preventive therapies for post-stroke depression: A meta-analysis of RCTs. Psychiatry Res. 284, 112670.

Hackshaw, A., 2009. Statistical Formulae for Calculating Some 95\% Confidence Intervals, A Concise Guide to Clinical Trials. BMJ Books 205-207.

Harrer, M., Adam, S.H., Baumeister, H., Cuijpers, P., Karyotaki, E., Auerbach, R.P., Kessler, R.C., Bruffaerts, R., Berking, M., Ebert, D.D., 2018. Internet interventions for mental health in university students: A systematic review and meta-analysis. Int. J. Methods Psychiatr. Res. e1759.

Hetrick, S.E., Cox, G.R., Merry, S.N., 2015. Where to Go from Here? An Exploratory Meta-Analysis of the Most Promising Approaches to Depression Prevention Programs for Children and Adolescents. International Journal of Environmental Research and Public Health 12, 4758-4795.

Hetrick, S.E., Cox, G.R., Witt, K.G., Bir, J.J., Merry, S.N., 2016. Cognitive behavioural therapy (CBT), third-wave CBT and interpersonal therapy (IPT) based interventions for preventing depression in children and adolescents. Cochrane Database Syst. Rev. CD003380.

Jemal, A., Fedewa, S.A., Ma, J., Siegel, R., Lin, C.C., Brawley, O., Ward, E.M., 2015. Prostate Cancer Incidence and PSA Testing Patterns in Relation to USPSTF Screening Recommendations. JAMA 314, 2054-2061.

Jiang, H.Y., Deng, M., Zhang, Y.H., Chen, H.Z., Chen, Q., Ruan, B., 2014. Specific serotonin reuptake inhibitors prevent interferon- $\alpha$-induced depression in patients with hepatitis C: a meta-analysis. Clin. Gastroenterol. Hepatol. 12, 1452-1460 e1453.

Kajka, N., Kulik, A., 2021. The Influence of Metacognitive Strategies on the Improvement of Reaction Inhibition Processes in Children with ADHD. Int J Environ Res Public Health 18.

Kloiber, S., Domschke, K., Ising, M., Arolt, V., Baune, B.T., Holsboer, F., Lucae, S., 2015. Clinical risk factors for weight gain during psychopharmacologic treatment of depression: results from 2 large German observational studies. J. Clin. Psychiatry 76, e802-e808.

Koletsi, D., Solmi, M., Pandis, N., Fleming, P.S., Correll, C.U., Ioannidis, J.P.A., 2020. Most recommended medical interventions reach $\mathrm{P}<0.005$ for their primary outcomes in meta-analyses. Int. J. Epidemiol. 49, 885-893.

Krishna, M., Lepping, P., Jones, S., Lane, S., 2015. Systematic review and meta-analysis of group cognitive behavioural psychotherapy treatment for sub-clinical depression. Asian Journal of Psychiatry 16, 7-16.

Kuhn, M., Scharfenort, R., Schümann, D., Schiele, M.A., Münsterkötter, A.L., Deckert, J., Domschke, K., Haaker, J., Kalisch, R., Pauli, P., Reif, A., Romanos, M., Zwanzger, P., Lonsdorf, T.B., 2016. Mismatch or allostatic load? Timing of life adversity differentially shapes gray matter volume and anxious temperament. Soc Cogn Affect Neurosci 11, 537-547.

Lenhard, W., Lenhard, A., 2016. Calculation of Effect Sizes. Psychometrica, Dettelbach (Germany).

Lépine, J.P., Briley, M., 2011. The increasing burden of depression. Neuropsychiatr Dis Treat 7, 3-7.

Lim, G.Y., Tam, W.W., Lu, Y., Ho, C.S., Zhang, M.W., Ho, R.C., 2018. Prevalence of Depression in the Community from 30 Countries between 1994 and 2014. Sci. Rep. 8, 2861. 
Loechner, J., Starman, K., Galuschka, K., Tamm, J., Schulte-Körne, G., Rubel, J., Platt, B., 2018. Preventing depression in the offspring of parents with depression: A systematic review and meta-analysis of randomized controlled trials. Clin. Psychol. Rev. 60, 1-14.

Ma, L., Zhang, Y., Cui, Z., 2019. Mindfulness-Based Interventions for Prevention of Depressive Symptoms in University Students: a Meta-analytic Review. Mindfulness 10, 2209-2224.

Mead, G.E., Hsieh, C.F., Lee, R., Kutlubaev, M.A., Claxton, A., Hankey, G.J., Hackett, M. L., 2012. Selective serotonin reuptake inhibitors (SSRIs) for stroke recovery. Cochrane Database Syst. Rev. 11. CD009286.

Murri, M.B., Ekkekakis, P., Menchetti, M., Neviani, F., Trevisani, F., Tedeschi, S., Latessa, P.M., Nerozzi, E., Ermini, G., Zocchi, D., Squatrito, S., Toni, G., Cabassi, A. Neri, M., Zanetidou, S., Amore, M., 2018. Physical exercise for late-life depression: Effects on symptom dimensions and time course. J. Affect. Disord. 230, 65-70.

Nair, U., Armfield, N.R., Chatfield, M.D., Edirippulige, S., 2018. The effectiveness of telemedicine interventions to address maternal depression: A systematic review and meta-analysis. J. Telemed. Telecare 24, 639-650.

Najt, P., Fusar-Poli, P., Brambilla, P., 2011. Co-occurring mental and substance abuse disorders: a review on the potential predictors and clinical outcomes. Psychiatry Res. 186, 159-164.

Nigatu, Y.T., Huang, J.P., Rao, S., Gillis, K., Merali, Z., Wang, J.L., 2019. Indicated Prevention Interventions in the Workplace for Depressive Symptoms: A Systematic Review and Meta-analysis. American Journal of Preventive Medicine 56, E23-E33.

Noto, M.N., Noto, C., Caribé, A.C., Miranda-Scippa, Â., Nunes, S.O., Chaves, A.C., Amino, D., Grassi-Oliveira, R., Correll, C.U., Brietzke, E., 2015. Clinical characteristics and influence of childhood trauma on the prodrome of bipolar disorder. Braz J Psychiatry 37, 280-288.

O'Connor, E., Senger, C.A., Henninger, M.L., Coppola, E., Gaynes, B.N., 2019. Interventions to Prevent Perinatal Depression Evidence Report and Systematic Review for the US Preventive Services Task Force. Jama-Journal of the American Medical Association 321, 588-601.

Oliver, D., Reilly, T.J., Baccaredda Boy, O., Petros, N., Davies, C., Borgwardt, S., McGuire, P., Fusar-Poli, P., 2019. What Causes the Onset of Psychosis in Individuals at Clinical High Risk? A Meta-analysis of Risk and Protective Factors. Schizophr. Bull.

Ollmann, T.M., Voss, C., Venz, J., Seidl, E., Hoyer, J., Kische, H., Pieper, L., Schiele, M.A., Domschke, K., Beesdo-Baum, K., 2020. The interaction of 5-HTT variation, recent stress, and resilience on current anxiety levels in adolescents and young adults from the general population. Depress. Anxiety.

Page, M.J., McKenzie, J.E., Bossuyt, P.M., Boutron, I., Hoffmann, T.C., Mulrow, C.D., Shamseer, L., Tetzlaff, J.M., Akl, E.A., Brennan, S.E., Chou, R., Glanville, J., Grimshaw, J.M., Hróbjartsson, A., Lalu, M.M., Li, T., Loder, E.W., Mayo-Wilson, E., McDonald, S., McGuinness, L.A., Stewart, L.A., Thomas, J., Tricco, A.C., Welch, V.A., Whiting, P., Moher, D., 2021. The PRISMA 2020 statement: An updated guideline for reporting systematic reviews. PLoS Med. 18, e1003583.

Patoz, M.C., Hidalgo-Mazzei, D., Blanc, O., Verdolini, N., Pacchiarotti, I., Murru, A., Zukerwar, L., Vieta, E., Llorca, P.M., Samalin, L., 2021. Patient and physician perspectives of a smartphone application for depression: a qualitative study. BMC Psychiatry 21, 65.

Petrie, K., Crawford, J., Baker, S.T.E., Dean, K., Robinson, J., Veness, B.G., Randall, J., McGorry, P., Christensen, H., Harvey, S.B., 2019. Interventions to reduce symptoms of common mental disorders and suicidal ideation in physicians: a systematic review and meta-analysis. Lancet Psychiatry 6, 225-234.

Rasing, S.P.A., Creemers, D.H.M., Janssens, J., Scholte, R.H.J., 2017. Depression and Anxiety Prevention Based on Cognitive Behavioral Therapy for At-Risk Adolescents: A Meta-Analytic Review. Frontiers in Psychology 8.

Salazar de Pablo, G., Catalan, A., Fusar-Poli, P., 2019. Clinical Validity of DSM-5 Attenuated Psychosis Syndrome: Advances in Diagnosis, Prognosis, and Treatment. JAMA Psychiatry.

Salazar de Pablo, G., Estradé, A., Cutroni, M., Andlauer, O., Fusar-Poli, P., 2021. Establishing a clinical service to prevent psychosis: What, how and when? Systematic review. Transl Psychiatry 11, 43.

Salazar de Pablo, G., Guinart, D., Cornblatt, B.A., Auther, A.M., Carrión, R.E., Carbon, M., Jiménez-Fernández, S., Vernal, D.L., Walitza, S., Gerstenberg, M., Saba, R., Lo Cascio, N., Brandizzi, M., Arango, C., Moreno, C., Van Meter, A., Correll, C.U., 2020a. Demographic and Clinical Characteristics, Including Subsyndromal Symptoms Across Bipolar-Spectrum Disorders in Adolescents. J. Child Adolesc. Psychopharmacol. 30, 222-234.

Salazar de Pablo, G., Vaquerizo-Serrano, J., Catalan, A., Arango, C., Moreno, C., Ferre, F. Shin, J.I., Sullivan, S., Brondino, N., Solmi, M., Fusar-Poli, P., 2020b. Impact of coronavirus syndromes on physical and mental health of health care workers: Systematic review and meta-analysis. J. Affect. Disord. 275, 48-57.

Salter, K.L., Foley, N.C., Zhu, L., Jutai, J.W., Teasell, R.W., 2013. Prevention of Poststroke Depression: Does Prophylactic Pharmacotherapy Work? Journal of Stroke \& Cerebrovascular Diseases 22, 1243-1251.

Sander, L., Rausch, L., Baumeister, H., 2016. Effectiveness of Internet-Based Interventions for the Prevention of Mental Disorders: A Systematic Review and MetaAnalysis. Jmir Mental Health 3.

Shea, B.J., Hamel, C., Wells, G.A., Bouter, L.M., Kristjansson, E., Grimshaw, J., Henry, D. A., Boers, M., 2009. AMSTAR is a reliable and valid measurement tool to assess the methodological quality of systematic reviews. J. Clin. Epidemiol. 62, 1013-1020.

Shorey, S., Chee, C.Y.I., Ng, E.D., Chan, Y.H., Tam, W.W.S., Chong, Y.S., 2018. Prevalence and incidence of postpartum depression among healthy mothers: A systematic review and meta-analysis. J. Psychiatr. Res. 104, 235-248.

Solmi, M., Fornaro, M., Ostinelli, E., Zangani, C., Croatto, G., Monaco, F., Krinitski, D., Fusar-Poli, P., Correll, C., 2020a. Safety of 80 antidepressants, antipsychotics, antiattention-deficit/hyperactivity medications and mood stabilizers in children and adolescents with psychiatric disorders: a large scale systematic meta-review of 78 adverse effects. World Psychiatry 19, 214-232.

Solmi, M., Miola, A., Croatto, G., Pigato, G., Favaro, A., Fornaro, M., Berk, M., Smith, L., Quevedo, J., Maes, M., Correll, C.U., Carvalho, A.F., 2020b. How can we improve antidepressant adherence in the management of depression? A targeted review and 10 clinical recommendations. Braz J Psychiatry.

Solmi, M., Radua, J., Stubbs, B., Ricca, V., Moretti, D., Busatta, D., Carvalho, A.F., Dragioti, E., Favaro, A., Monteleone, A.M., Shin, J.I., Fusar-Poli, P., Castellini, G., 2020c. Risk factors for eating disorders: an umbrella review of published metaanalyses. Braz J Psychiatry.

Ssegonja, R., Nystrand, C., Feldman, I., Sarkadi, A., Langenskiold, S., Jonsson, U., 2019. Indicated preventive interventions for depression in children and adolescents: A meta-analysis and meta-regression. Preventive Medicine 118, 7-15.

Stockings, E.A., Degenhardt, L., Dobbins, T., Lee, Y.Y., Erskine, H.E., Whiteford, H.A., Patton, G., 2016. Preventing depression and anxiety in young people: a review of the joint efficacy of universal, selective and indicated prevention. Psychol. Med. 46, 11-26.

Tan, L., Wang, M.J., Modini, M., Joyce, S., Mykletun, A., Christensen, H., Harvey, S.B., 2014. Preventing the development of depression at work: a systematic review and meta-analysis of universal interventions in the workplace. BMC Med. 12, 74.

Ten Have, M., de Graaf, R., van Dorsselaer, S., Tuithof, M., Kleinjan, M., Penninx, B.W.J. H., 2018. Recurrence and chronicity of major depressive disorder and their risk indicators in a population cohort. Acta Psychiatr. Scand. 137, 503-515.

U.S. Preventive Services Task Force, 2012. Grade Definitions. U.S. Preventive Services Task Force. Rockville, US.

van Zoonen, K., Buntrock, C., Ebert, D.D., Smit, F., Reynolds, C.F., Beekman, A.T.F., Cuijpers, P., 2014. Preventing the onset of major depressive disorder: A metaanalytic review of psychological interventions. International Journal of Epidemiology 43, 318-329.

Vieta, E., Salagre, E., Grande, I., Carvalho, A.F., Fernandes, B.S., Berk, M., Birmaher, B., Tohen, M., Suppes, T., 2018. Early Intervention in Bipolar Disorder. American Journal of Psychiatry 175, 411-426.

Werner-Seidler, A., Perry, Y., Calear, A.L., Newby, J.M., Christensen, H., 2017. Schoolbased depression and anxiety prevention programs for young people: A systematic review and meta-analysis. Clin. Psychol. Rev. 51, 30-47.

Yap, M.B.H., Morgan, A.J., Cairns, K., Jorm, A.F., Hetrick, S.E., Merry, S., 2016. Parents in prevention: A meta-analysis of randomized controlled trials of parenting interventions to prevent internalizing problems in children from birth to age 18 . Clinical Psychology Review 50, 138-158.

Yi, Z.M., Liu, F., Zhai, S.D., 2010. Fluoxetine for the prophylaxis of poststroke depression in patients with stroke: a meta-analysis. Int. J. Clin. Pract. 64, 1310-1317.

Young, L.M., Pipingas, A., White, D.J., Gauci, S., Scholey, A., 2019. A Systematic Review and Meta-Analysis of B Vitamin Supplementation on Depressive Symptoms. Anxiety, and Stress: Effects on Healthy and 'At-Risk' Individuals. Nutrients 11.

Zahid, J.A., Grummedal, O., Madsen, M.T., Gögenur, I., 2020. Prevention of depression in patients with cancer: A systematic review and meta-analysis of randomized controlled trials. J. Psychiatr. Res. 120, 113-123.

Zhang, J., Yu, K.F., 1998. What's the relative risk? A method of correcting the odds ratio in cohort studies of common outcomes. JAMA 280, 1690-1691.

Zhou, S., Liu, S., Liu, X., Zhuang, W., 2020. Selective serotonin reuptake inhibitors for functional independence and depression prevention in early stage of post-stroke: A meta-analysis. Medicine (Baltimore). 99, e19062. 